\title{
SIGNIFICADO DE LA FE PÚBLICA EN LA PRUEBA POR MEDIO DE DOCUMENTOS PÚBLICOS*
}

\section{Claudio Meneses Pacheco**}

RESUMEN: El presente trabajo contiene una explicación de la fe pública como elemento de la prueba por documentos públicos, que se caracteriza por la presencia de un conjunto de disposiciones legales que regulan el proceso de confección de documentos con el objeto de garantizar la autenticidad de estos. La fe pública la entendemos como una institución jurídica cuyo fundamento es la seguridad del tráfico, que se proyecta en el campo probatorio a través de normas de valoración legal. Sobre la base de lo anterior, para efectos de la prueba en los procesos civiles concluimos que es necesario formular una distinción entre dos clases de documentos públicos: unos provistos de fe pública y otros que son el resultado del ejercicio de funciones públicas. Considerando las mayores garantías que rodean al proceso de confección de documentos dotados de fe pública, sostenemos que estos deben poseer más valor probatorio que los elaborados con motivo del ejercicio de funciones públicas.

PALABRAS CLAVE: Documento público; Fe pública; Función pública; Valoración legal de la prueba; Autenticidad documental.

\section{MEANING OF PUBLIC TRUST IN PUBLIC DOCUMENTARY EVIDENCE}

ABSTRACT: This paper contains an explanation of public trust as an element of public documentary evidence, which can be characterized by the presence of a group of legal provisions that regulate the elaboration process of documents in order to guarantee their authenticity. We understand public trust as a legal institution that seeks to give certainty in

Fecha de recepción: 8 de noviembre de 2016.

Fecha de aceptación: 25 de enero de 2017.

** Profesor de Derecho Procesal de la Universidad de Valparaíso (Chile). Magíster en Derecho Público por la Universidad de los Andes (Chile). Doctor en Derecho por la Universidad de los Andes (Chile). Correo electrónico: claudio.meneses@uv.cl 
trading and that acts in the evidentiary field through legal valuation rules. Based on the aforementioned regarding evidence in civil proceedings, we conclude that a distinction must be made between two kinds of public documents: those that are provided of public trust and those that are a result of the exercise of public functions. Considering the higher guarantees that surround the elaboration process of documents that are provided with public trust, we contend that these must have more probative value than those documents elaborated as a consequence of the exercise of public functions.

KEY WORDS: Public document; Public trust; Public function; Legal valuation of evidence; Documentary authenticity.

Sumario: Introducción 1) Distintos criterios para definir la fe pública (1.1.) Planteamiento (1.2.) Fe pública según el criterio publicistico-normativo en una acepción objetiva (1.3.) Fe pública según el criterio publicístico-normativo en una acepción subjetiva (1.4.) Fe pública según el criterio psicológico-naturalista 2) Noción y caracteristicas de la fe pública que concurre en la prueba por medio de documentos públicos (2.1.) Noción (2.2.) Fe pública como institución jurídica (2.2.1.) Explicación (2.2.2.) Documentos electrónicos suscritos mediante "firma electrónica avanzada" (2.2.3.) La notaría como "institución" o como "ficio" (2.3.) La fe pública se compone de un conjunto de disposiciones legales cuyo objeto central es garantizar la autenticidad de los documentos públicos (2.4.) La fe pública tiene como fundamento la seguridad del tráfico jurídico (2.5.) La fe pública se proyecta en el campo probatorio a través de normas de valoración legal de los documentos públicos 3) Documentos públicos que son confeccionados durante el ejercicio de funciones públicas ("documentos oficiales") (3.1.) Planteamiento (3.2.) Identificación de los conceptos de fe pública y función pública en la doctrina y jurisprudencia chilenas (3.3.) La tesis de Parejo en la doctrina española 4) Necesidad de distinguir la fe pública y la función pública como elementos de la prueba por medio de documentos públicos (4.1.) Algunos antecedentes históricos y comparados (4.2.) Diferenciación del valor probatorio (4.3.) Necesidad de evitar privilegios probatorios (4.4.) Seguridad jurídica y principio de protección de la confianza legitima 5) Aspectos que permiten hacer la distinción entre fe pública y función pública en la prueba documental pública (5.1.) Características del procedimiento de confección documental (5.2.) Distinción entre el autor del documento y el autor de la declaración contenida en el documento (5.3.) Ausencia de procedimiento especial y confusión de autoría en los documentos confeccionados durante el ejercicio de funciones públicas. Conclusiones. 


\section{INTRODUCCIÓN}

El concepto de documento público puede ser asociado al de fe pública. Es lo que encontramos en el art. 1699 inc. $1^{\circ} \mathrm{CC}$, que define al instrumento público como el "autorizado con las solemnidades legales por el competente funcionario". Cuando este precepto exige que el instrumento público tenga la autorización de un funcionario competente y que, además, cumpla con las solemnidades legales, se está refiriendo a exigencias propias de la dación de fe pública en la confección de esta clase documental. La autorización de un documento es la actividad reglada encaminada a dotarlo de fe pública.

Ahora bien, para comprender la relación que media entre documento público y fe pública es necesario formular varias precisiones conceptuales, algunas de las cuales serán examinadas en este trabajo desde el punto de vista de la prueba en los procesos civiles. Debemos advertir que uno de los temas relevantes en este estudio atañe a la noción de documento público como medio de prueba, lo que en el caso de la legislación nacional implica pronunciarse en torno al sentido y alcance de la definición del art. 1699 inc. $1^{\circ}$ CC. Este es un asunto que no podremos abordar aquí, porque requiere de un estudio histórico y dogmático que excede los límites del presente artículo. Por el momento, solo podemos señalar que en nuestro parecer la aludida definición legal tiene un significado preciso y acotado que no cabe aplicar a todas las hipótesis de pruebas documentales públicas. Esta norma se refiere concretamente a documentos públicos solemnes autorizados por ministros de fe pública cuyo contenido recae sobre actos jurídicos de Derecho Privado. Por tal razón, los instrumentos públicos hay que entenderlos como una especie de documento público.

En consecuencia, al menos desde un punto de vista probatorio, cabe considerar la presencia de otras clases de documentos públicos en los que concurre la fe pública de una forma distinta a la señalada en el art. 1699 inc. $1^{\circ} \mathrm{CC}$ (sin la intervención de ministros de fe y sin la presencia de solemnidades legales). Un ejemplo es el documento electrónico suscrito mediante firma electrónica avanzada, donde la fe pública no emana de la intervención de un fedatario ni de la presencia de solemnidades legales, sino del conjunto de normas que regula la confección documental y asegura su autenticidad.

Pero además es posible distinguir una modalidad diversa en la que los documentos públicos no están dotados de fe pública sino que son el resultado del ejercicio de funciones públicas. Por lo general, estos últimos reciben el nombre de "documentos oficiales", que desde una óptica proba- 
toria pueden ser calificados como documentos públicos al estar rodeados de elementos que permiten dar por establecida su autenticidad sin necesidad de prueba complementaria.

A continuación explicaremos en qué consiste la fe pública en materia de prueba documental pública, y cuáles son las principales diferencias que existen entre los documentos revestidos de dicho atributo y los que son fruto del ejercicio de funciones públicas, en particular en el ámbito de la valoración. Estas explicaciones pueden servir de base para un estudio más completo sobre la noción de documento público, sus características como medio de prueba y las técnicas de valoración legal de esta evidencia.

\section{1) Distintos CRITERIOS PARA DEFINIR LA FE PÚBLICA}

\section{(1.1.) Planteamiento}

Los conceptos de documento público y fe pública tienen vinculación, al punto que algunos autores señalan que la única forma de entender el significado de aquel es definiendo a esta. "La comprensión de lo que es un documento público pasa por la de la fe pública", afirma MonTERo Aroca ${ }^{1}$. El problema es que la fe pública es un concepto evolutivo, cuyo significado se encuentra asociado al modelo político-jurídico de una sociedad y a los cambios que dicho modelo experimente en el tiempo, razón por la cual no puede afirmarse que exista una única noción.

No hay claridad sobre sus orígenes históricos. Algunos afirman que ya en el Derecho romano justinianeo existía una regulación de la fe pública y de los tabelliones como ministros $\mathrm{de}^{2} \mathrm{fe}^{2}$. Otros en cambio indican que este concepto recién habría aparecido a fines del siglo XVIII con el trabajo de Filangieri ${ }^{3}$, al menos en su acepción como bien jurídico protegido por el Derecho Penal ${ }^{4}$.

1 Montero Aroca, Juan (2012) La prueba en el proceso civil. 7a edición. Navarra: Civitas / Thomson Reuters / Aranzadi, 625 pp., p. 287.

2 Sobre este debatido tema, destacamos las explicaciones de Fernández de Buján, Antonio (2001) "Fides publica e instrumenta publice confecta en Derecho romano". Revista de Estudios Latinos. Universidad Complutense de Madrid. No 1, pp. 189-200.

3 Filangieri, Cayetano (1823) Ciencia de la legislación. Traducción de Juan Ribera. 2a edición. Burdeos: Imprenta P. Beaume. T. III, 364 pp., p. 260.

$4 \quad$ En este sentido, Etcheberry, Alfredo (1961) "El objeto jurídico de los delitos de falsedad documental". En Revista de Ciencias Penales. Santiago: Instituto de Ciencias Penales-Chile. T. XX, No 1, pp. 33-66, p.38; De Rivacoba y Rivacoba, Manuel (1986) "Objeto jurídico y sujeto pasivo de la falsificación de moneda”. En Revista Doctrina Penal. Año 9 № s 33-34, pp. 41-53, p. 42; Villacampa Estiarte, Carolina (1999) La falsedad documental: análisis juridico-penal. Barcelona: Cedecs, 906 pp., p. 43. 
Tampoco hay coincidencia sobre los verdaderos alcances de la fe pública en el campo jurídico. Mientras algunos estiman que constituye "uno de los más preciosos instrumentos de la convivencia humana en el orden

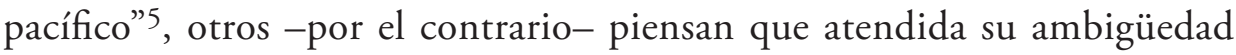
es nada más que una "una esfinge semejante a un manojo de ortigas"6.

Muy vinculado con lo anterior, existe una pluralidad de sedes, objetos y finalidades asociados a la fe pública, siendo los principales ámbitos el penal y el notarial, en cada uno de los cuales las nociones empleadas son disímiles. De hecho, para Couture entre el concepto de fe pública como bien jurídico protegido por el Código Penal y la noción utilizada en el Derecho Notarial, no solo se producen diferencias sino una verdadera antítesis $^{7}$, lo que revela la disparidad de pareceres a la que hacemos mención. A su turno, los penalistas siguen discutiendo en cuanto a si la fe pública efectivamente puede ser considerada un bien jurídico tutelado por los delitos de falsedades documentales ${ }^{8}$, lo que también es demostrativo de lo que afirmamos.

5 Couture, Eduardo J. (1989) "El concepto de fe pública (Introducción al estudio del Derecho notarial)". En Estudios de Derecho Procesal Civil. $3^{a}$ edición. Buenos Aires: Depalma. T. II, pp. 13-25, p. 122.

6 Rivacoba (1986) 42, refiriéndose a los comentarios críticos de Antolisei y a Jiménez HUERTA.

Couture (1989) 19.

8 Sobre esta discusión y la abundante producción dogmática, destacamos los siguientes trabajos: Quintano Ripollés, Antonio (1952) La falsedad documental. Madrid: Reus, 270 pp., pp. 77-82; Etcheberry (1961) 33-66; Etcheberry, Alfredo (i 1998) Derecho Penal. $3^{a}$ Edición. Santiago: Editorial Jurídica de Chile. T. IV, 382 pp., pp. 131-136; Villacampa (1999) 25-97; Rodríguez Collao, Luis; Vera Vega, Jaime (2004) "El bien jurídico protegido en los delitos de falsedad". Revista Escuela de Derecho. Universidad Católica de Temuco, No 5, pp. 109-135; Vargas Pinto, Tatiana (2013) Falsificación de instrumento privado. Un estudio práctico entre la falsificación y la estafa. Santiago: LegalPublishing / Thomson Reuters, 179 pp., pp. 108-135; MaYer Lux, Laura (2014) "La falsificación de instrumentos privados: ¿una estafa especial?”. Revista de Derecho. Universidad Austral de Chile, Vol. 27, № 2, pp. 217-241, pp. 230 y 231; Rojas Aguirre, Luis Emilio (2012) "Historia dogmática de la falsedad documental". Revista de Derecho. Pontificia Universidad Católica de Valparaíso. $\mathrm{N}^{\circ} 39, \mathrm{~N}^{\circ}$ 2, pp. 545-583, pp. 547-582; Rojas Aguirre, Luis Emilio (2014 a) "Falsedad documental como delito de engaño". Revista Chilena de Derecho. Pontificia Universidad Católica de Chile, Vol. 41, No 2, pp. 523-554, pp. 545-551; Rojas Aguirre, Luis Emilio (2014 b) "Deconstrucción del método dominante de comprensión de los delitos de falsedad documental". Política Criminal, Vol. 9, No 18, art. 6, pp. 477-520, pp. 481-485. Disponible en [http://www.politicacriminal.cl/Vol_09/n_18/Vol19N18A6.pdf]; Rojas Aguirre, Luis Emilio (2015) "Falsedad documental como delito contra el derecho a la verdad". Revista de Estudios de la Justicia. Universidad de Chile. No 22, pp. 143-179, pp. 145-165; Rojas Aguirre, Luis Emilio (2016) "Iter criminis sin solución de continuidad en los delitos de falsedad documental y uso malicioso de documento falso". En Cárdenas Aravena, C.; Ferdman Niedmann, J. (coordinadores). El Derecho Penal como teoría y como práctica. Libro en homenaje a Alfredo Etcheberry Orthusteguy. Santiago: Thomson Reuters, pp. 777-796, pp. 781-783. 
Semejante división de opiniones transforma a la fe pública en una materia de difícil comprensión. Una "vexata quaestio", como afirmaba Rivacoba9. En un intento de sistematización, siguiendo a Villacampa podemos mencionar tres postulados teóricos que explican de manera diversa el sentido de esta figura. Son los criterios publicístico-normativo en una acepción objetiva, publicístico-normativo en una acepción subjetiva, y psicológico-naturalista ${ }^{10}$, que explicaremos a continuación en relación con los documentos públicos.

\section{(1.2.) FE PÚBLICA SEGÚN EL CRITERIO PUBLICÍSTICO-NORMATIVO EN UNA ACEPCIÓN OBJETIVA}

Según este criterio, la fe pública debe ser entendida como una certeza atribuida por el ordenamiento legal a los documentos públicos, de manera que lo verdaderamente importante es la eficacia inherente a la cosa (documento público), asignada por la ley. La presencia física de ministros de fe, por tanto, no es un presupuesto esencial ${ }^{11}$.

En la doctrina notarial española, NúŃEz Lagos pensaba de este modo. En su opinión, una cosa adquiere la calidad de documento público cuando se encuentra investida de un valor o grado de eficacia llamado fe pública. Esta cualidad no puede tener nunca un sentido subjetivista ni puede estar atribuida a un funcionario; su sentido es objetivo, inherente a la cosa misma. "La cosa -prueba- es el objeto valorado o portador de valor. La fe pública, el valor mismo que a la cosa da la ley [...] Nadie, al referirse al funcionario, puede decir que este tenga fe pública, más que en un sentido figurado, refiriéndose al autor del documento con fe pública, pues todo documento público, esto es, que hace fe porque lleva en sí fe pública, tiene necesariamente un autor en ejercicio de una actividad pública" 12 .

Este enfoque teórico está presente en las opiniones de Romero y Martínez acerca de las modificaciones introducidas al notariado por la

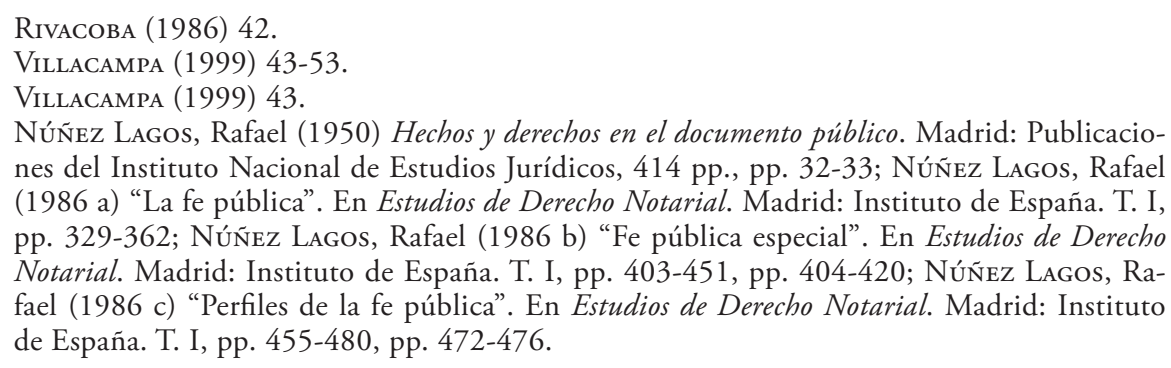
nes del Instituto Nacional de Estudios Jurídicos, 414 pp., pp. 32-33; NúŃEz Lagos, Rafael (1986 a) "La fe pública". En Estudios de Derecho Notarial. Madrid: Instituto de España. T. I, pp. 329-362; NúŃEz LaGos, Rafael (1986 b) "Fe pública especial”. En Estudios de Derecho Notarial. Madrid: Instituto de España. T. I, pp. 403-451, pp. 404-420; Núñez Lagos, Rafael (1986 c) "Perfiles de la fe pública". En Estudios de Derecho Notarial. Madrid: Instituto de España. T. I, pp. 455-480, pp. 472-476. 
Ley No 18.181 de 1982, que a juicio de estos autores cambiaron sustancialmente la visión de la fe pública que existía en el ordenamiento chileno, a fin de adaptarla al desarrollo de la economía. La figura del notario adquirió el carácter de una institución jurídica cuya finalidad es avalar y dar fe de la autenticidad de los documentos que se les presenten o que se otorguen ante ellos.

Romero y Martínez indican que a partir del año 1982 el procedimiento de confección de las escrituras públicas ya no se compone de los mismos elementos heredados de la tradición medieval, pues ha dejado de ser necesario que la escritura sea redactada "per manum publicam facta" y extendida "in publicam forma". Tampoco es indispensable que el notario esté en contacto directo con el suscriptor al momento de autorizarse una firma estampada en un documento privado, en los términos que señalan los arts. $401 \mathrm{~N}^{\circ} 10$ COT y 425 inc. 10 COT. Lo que importa es que la notaría funcione como una institución destinada a avalar la fe pública y resguardar la seguridad jurídica ${ }^{13}$. Así, para estos autores -con quienes coincidimos- la función notarial tiene por objeto central la autenticación de documentos, y no el asesoramiento de las partes otorgantes. Por lo mismo, a partir de la citada reforma el documento público notarial pasó a caracterizarse fundamentalmente por el hecho de estar autorizado por el notario con arreglo a la ley, lo que se nota con especial claridad en la modificación introducida en materia de redacción de escrituras públicas, que dejó de estar a cargo del notario ${ }^{14}$.

Este planteamiento ha estado presente en la jurisprudencia, tanto al calificar a la notaría como una estructura organizacional, como al estimar que las autorizaciones notariales no requieren la presencia del suscriptor del documento al momento de practicar la respectiva certificación.

En relación con el estatuto jurídico de las notarías, la Corte de Apelaciones de Santiago mediante una sentencia de 30 de julio de 2008 estimó que correspondía a una "estructura organizacional"15, enfatizando su carácter institucional por sobre la figura del notario. Según podremos profundizar más abajo, si bien este último criterio no ha sido compartido por la Corte Suprema, de todos modos hallamos cierta coincidencia en

13 Romero Seguel, Alejandro; Martínez Estay, José Ignacio (2005) "Sobre la pretendida obligación de firmar ante los notarios los instrumentos públicos y privados". Revista de la Asociación de Notarios y Conservadores de Chile. Santiago, pp. 13-22, p. 19.

14 Romero/ Martínez (2005) 18-19.

15 Corte de Apelaciones de Santiago. 30 de julio de 2008. Rol No 4149-2007. "Landman Rodríguez, María con Segunda Notaría de Providencia”. Disponible en: http://microjuris.cl/ getContent?reference=MJCH_MJJ17961\&links=[MJJ17961] [fecha de visita 9 de julio de 2016], c. $1^{\circ}$. 
cuanto al aspecto institucional de la función notarial, ya que se reconoce que la notaría tiene la condición jurídica de "oficio". Este concepto, como comprobaremos, tienen una raigambre histórica que puede relacionarse con la perspectiva que comentamos.

En lo que respecta a las autorizaciones notariales, es pertinente la interpretación dada por la Corte Suprema a la frase "cuya firma aparezca autorizada por un notario" contenida en el art. 434 No 4 inc. 2o CPC. En sentencias de 4 de agosto de 1980, 29 de enero de 1992, 17 de marzo de 2009, 30 de enero de 2012 y 17 de julio de 2014, la Corte ha sostenido que tal norma no exige la presencia del obligado a la firma del respectivo documento (letras de cambio, pagarés y cheques), bastando la certificación del notario que permite legalizarlo y atribuirle fe pública ${ }^{16}$. Las últimas dos sentencias -que luego analizaremos- han profundizado sobre una serie de rubros que armonizan con esta perspectiva, en especial al considerar que el propósito de la intervención notarial es amparar la autenticidad del documento al dotarlo de fe pública ${ }^{17}$.

16 Corte Suprema. 4 de agosto de 1980. "Banco de Chile con Jimeno Valenzuela, Leonardo”. Fallos del Mes. No 261, pp. 236-238, cs. 3o y 4o, p. 238; Corte Suprema. 29 de enero de 1992. "Banco de Chile con Valdés V., Gerardo y otro". Revista de Derecho y Jurisprudencia. T. 89, sec. $1^{\mathrm{a}}$, pp. 6-14, c. $11^{\mathrm{o}}$, p. 11; Corte Suprema. 17 de marzo de 2009. Rol No 602-08. "Banco Consosur con Huichalaf Concha, Orompello". Disponible en: http://microjuris.cl/getContent?reference=MJCH_MJJ19777\&links=[MJJ19777] [fecha de visita 9 de julio de 2016], c. 4o; Corte Suprema. 30 de enero de 2012. Rol No 12716-11. "Banco de Crédito e Inversiones con Sociedad Comercializadora de Productos Forestales Limitada". Disponible en: http://microjuris.cl/getContent?reference=MJCH_ MJJ30844\&links=[MJJ30844] [fecha de visita 9 de julio de 2016], cs. 60-11 ${ }^{\circ}$; CorTE Suprema. 17 de julio de 2014. Rol No 7240-2014. "Banco del Estado de Chile con Procam 3 S.A. y otros”. Disponible en: http://microjuris.cl/getContent?reference=MJCH_ MJJ38062\&links=[MJJ38062] [fecha de visita 9 de julio de 2016], cs. 6o-8o; Corte SuPREMA. 17 de julio de 2014. Rol No 13.148-2013. "Banco Santander Chile con Inversiones e Inmobiliaria G y L”. Disponible en: http://microjuris.cl/getContent?reference=MJCH_ MJJ38050\&links=[MJJ38050] [fecha de visita 9 de julio de 2016], c. 6º . En igual sentido, pueden consultarse, entre varias otras, las siguientes sentencias: CoRTE DE APELACIONES DE Santiago. 25 de octubre de 1991. "Citibank N.A. con Americana Travel Limitada". Revista de Derecho y Jurisprudencia. T. 88 , sec. $2^{\mathrm{a}}$, pp. 129-131, c. $1^{\circ}$, p. 130; CorTe De ApelaCioNes de Santiago. 6 de noviembre de 2015. Rol No 7891-2015. "González Landeta, Ignacio con Sistemas de Seguridad y Servicios Limitada”. Disponible en: http://microjuris.cl/ getContent?reference=MJCH_MJJ42908\&links=[MJJ42908] [fecha de visita 9 de julio de 2016], cs. 5o y 6o; Corte de Apelaciones de Santiago. 9 de noviembre de 2015. Rol No 7709-2015. “Banco Bilbao Vizcaya Argentaria Chile con Ríos León, María”. Disponible en: http://microjuris.cl/getContent?reference=MJCH_MJJ42934\&links=[MJJ42934] [fecha de visita 9 de julio de 2016], c. 5º.

17 Sin embargo, dejamos constancia que en ocasiones la jurisprudencia ha concluido que la actividad notarial también recae sobre aspectos de fondo del acto jurídico documentado, lo que se vincula más bien con la validez y eficacia de la relación jurídica sustantiva. En este sentido se pronunció la Corte de Apelaciones de Chillán en sentencia de 17 de febrero de 2016, al señalar que la obligación del notario, como ministro de fe, se extiende "hasta el punto de precaver la ineficacia o nulidad de un acto juridico que se presenta para ser otorgado 
La dimensión objetiva de la fe pública también puede relacionarse con las explicaciones de los penalistas Rivacoba y Guzmán Dálbora, quienes conciben a esta figura como una confianza generalizada en la autenticidad y valor de ciertos objetos (entre ellos, los documentos públicos), que es impuesta por el Estado, ya sea directamente, a través de instituciones o de la actuación de funcionarios públicos ${ }^{18}$. Otros autores asocian el concepto de fe pública con la seguridad del tráfico jurídico y con el valor probatorio que la ley atribuye a los documentos públicos en sí mismos, en especial en cuanto a su autenticidad. Piensan de este modo Etcheberry, Gallegos, Garrido Montt, Politoff, Matus y RamíREZ ${ }^{19}$.

En la misma línea argumental se sitúa una sentencia de 3 de mayo de 1996 de la Corte de Apelaciones de San Miguel, que vinculó la fe pública con la seguridad del tráfico jurídico: "[La] fe pública se identifica por la doctrina penal moderna con la seguridad y normalidad del tráfico jurídico, concepto este que se halla ligado estrechamente a la autenticidad de determinados elementos a los cuales la ley ha atribuido ciertos efectos jurídicos de obligatoriedad general, en especial, la producción de confianza en la genuinidad de ellos" 20 .

Como se aprecia, estas interpretaciones atribuyen relevancia a aspectos objetivos de los documentos públicos que en nuestra opinión deben ser destacados en el plano de las pruebas. La referencia a la institución notarial, la estructura organizacional de la notaría, el oficio notarial, la seguridad del tráfico y la autenticidad documental, son fundamentales para entender la fe pública como elemento de las pruebas documentales públicas.

en su oficio" (Corte de Apelaciones de Chillán. 17 de febrero de 2016. Rol No 94-16. "Carrasco Fuentes, Raúl con Tejos Henríquez, Joaquín”. Disponible en: http://microjuris.cl/ getContent?reference=MJCH_MJJ43595\&links=[MJJ43595] [fecha de visita 9 de julio de 2016]., c. $\left.8^{\circ}\right)$.

Rivacoba (1986) 42-44; Guzmán Dálbora, José Luis (2009) "Falsedad documental y supresión de actuaciones en expedientes judiciales". En Estudios y defensas penales. $3^{a}$ edición. Santiago: LegalPublishing, pp. 511-523, p. 512.

19 Etcheberry (1961) 56-62; Etcheberry (1998) 136; Gallegos Sanhueza, Walter (2000) Crimenes y simples delitos contra la fe pública. Santiago: Editorial Jurídica Aremi, 288 pp., pp. 103-104; Garrido Montt, Mario (2008) Derecho Penal. Parte especial. 4a edición. Santiago: Editorial Jurídica de Chile. T. IV, 259 pp., p. 14; Politoff Lifschitz, Sergio; Matus Acuña, Jean Pierre; Ramírez González, María (2009) Lecciones de Derecho Penal chileno. Parte especial. 2a edición. Santiago: Editorial Jurídica de Chile, 689 pp., p. 555.

20 Corte de Apelaciones de San Miguel. 3 mayo 1996. "contra Contreras Rolack, Patricio Hernán”. Revista de Derecho y Jurisprudencia. T. 93, sec. 4a , pp. 152-155, parte transcrita en c. $9^{\circ}$, p. 154 . 


\section{(1.3.) FE PÚBLICA SEGÚN EL CRITERIO PUBLICÍSTICO-NORMATIVO EN UNA ACEPCIÓN SUBJETIVA}

Este criterio se concentra en los ministros de fe. Si bien comparte el postulado básico anterior en cuanto a la importancia que reviste el valor atribuido por la ley a los documentos públicos, hace reposar esta cualidad en los ministros de fe y en la intervención que les corresponde en el proceso de formación documental ${ }^{21}$.

En la doctrina extranjera, este planteamiento ha sido defendido por autores como Carrara, Couture y Rodríguez Adrados ${ }^{22}$. En nuestro país, Claro Solar, Santa Cruz, Díaz Sanguesa, Vidal Domínguez y Rioseco, estiman que el valor legal que los arts. 1700 y 1706 CC atribuyen a los instrumentos públicos deriva de la fe pública que le imprimen los ministros de $\mathrm{fe}^{23}$. En similar sentido opina GaEte a propósito de los documentos suscritos mediante firma electrónica avanzada, que en su parecer no deberían tener el valor probatorio indicado por el art. $5^{\circ} \mathrm{No} 2$ Ley No 19.799 de 2002 (que, en lo medular, es el mismo establecido por los arts. 1700 y $1706 \mathrm{CC}$ ), considerando que las entidades certificadoras de esta clase de firma no poseen la calidad de ministros de fe. Para este autor el único capaz de dotar de certeza a la fecha y autenticidad de un documento es un ministro de fe y, en especial, un notario, por lo que las certificaciones emanadas de las antedichas entidades carecerían del mérito propio de la fe pública ${ }^{24}$.

En la jurisprudencia, podemos citar los fallos de 6 de agosto de 1963 y de 26 de mayo de 1981 de la Corte de Apelaciones de Santiago, y las sentencias de 18 de octubre de 2000 y de 30 de marzo de 2010 de la Corte Suprema, en los cuales el concepto de documento público aparece asociado a la fe pública otorgada por ministros de fe. En la sentencia de

\footnotetext{
21 Villacampa (i 999) 43-48.

22 Carrara, Francesco (1964) Programa de Derecho Criminal. Traducción de J. Ortega y J. Guerrero. Bogotá: Temis, vol. VII, 527 pp., pp. 1-8; Couture (1989) 37-38, 47-48; Rodríguez Adrados, Antonio (1996) "Fe pública". En Escritos Jurídicos. Madrid: Colegios Notariales de España. Vol. III, pp. 175-186.

23 Claro Solar, Luis (1992) Explicaciones de Derecho Civil chileno y comparado. Las obligaciones. Santiago: Editorial Jurídica de Chile. Vol. VI, t. XII, 822 pp., p. 671; Santa CruZ SeRrano, Víctor (1942) "El instrumento público". Revista de Derecho y Jurisprudencia. T. 39, pp. 5-60, p. 6; Díaz Sanguesa, Alfonso (1957) La fe pública y el Derecho notarial. Santiago: Editorial Universitaria, 154 pp., pp. 13-17; Vidal DomíngueZ, Ignacio (1997) Derecho notarial chileno. Santiago: Editorial Fallos del Mes, 517 pp., p. 17; Rioseco Enríquez, Emilio (2002) La prueba ante la jurisprudencia. Derecho Civil y Procesal Civil. 4a edición. Santiago: Editorial Jurídica de Chile. T. I, 493 pp., p. 275.

24 Gaete González, Eugenio (2009) Instrumento público electrónico. $3^{a}$ edición. Barcelona: Bosch, 551 pp., pp. 515-516.
} 
6 de agosto de 1963, la Corte de Apelaciones de Santiago sostuvo que un certificado de notas extendido con el sello y la firma de la Directora de un Liceo Fiscal no constituye un documento público, pues con su falsificación "no se ofende la fe pública garantizada por la ley" 25 . La misma Corte, mediante sentencia de 26 de mayo de 1981, señaló que la distinción entre documentos públicos y privados está basada en la presencia o ausencia de fe pública: "el documento privado se caracteriza, substancialmente, por no estar protegido por la fe pública que se debe a los instrumentos públicos y que proviene de la participación de un funcionario público en su formación, cumpliendo formalidades especiales" 26 . En el fallo de 18 de octubre de 2000, la Corte Suprema concluyó que el documento consistente en el "libro de novedades de guardia” de un Centro de Detención Preventiva no tenía el carácter de documento público, "como quiera que evidentemente el registro llevado por la guardia de un establecimiento carcelario, a través de simples anotaciones de orden interno del penal y sobre circunstancias ocurridas en la misma vigilancia funcionaria, son materias ajenas al debido resguardo de la fe pública [...]"27. En la sentencia de 30 de marzo de 2010, la Corte Suprema resolvió que la concurrencia de la fe pública es esencial para poder calificar a un documento como público, razón por la cual ciertos certificados emitidos por la Autoridad Marítima no admitían tal calificación: "no todo instrumento suscrito por funcionario o empleado estatal es un documento público, pues para ello son imprescindibles los requisitos de la 'fe pública' y de las solemnidades que fije la ley para expedirlos" 28 .

Ahora bien, en la doctrina nacional pueden distinguirse dos opiniones a propósito de las calidades que debe tener el oficial público que interviene en la confección del documento. Para un grupo de autores la definición de documento público se halla indisolublemente asociada a los ministros de fe y a la fe pública otorgada por estos; Claro Solar y RioSECO son dos exponentes de esta interpretación. El otro enfoque extiende las referidas nociones e incluye a los funcionarios públicos; fue lo que sostuvo SANTA CRUz, quien al explicar los fundamentos de las normas sobre valoración legal de los instrumentos públicos se refirió a la fe pública que

25 Corte de Apelaciones de Santiago. 6 agosto 1963. "contra Foncea C. Luis Alberto y otra”. Revista de Derecho y Jurisprudencia. T. 60, sec. 4a, pp. 365-368, c. 4º, p. 369. Corte de Apelaciones de Santiago. 26 mayo 1981. "Vanni, Laura con Ortiz, Humberto". Revista de Derecho y Jurisprudencia. T. 78, sec. 2a, pp. 67-69, c. 6º p. 68.

27 Corte Suprema. 18 octubre 2000. "contra Delpino Abello, Luis". Revista de Derecho y Jurisprudencia. T. 97, sec. $4^{\text {a }}$, pp. 318-322, cs. $6^{\circ}$ y 7o, p. 320.

28 Corte Suprema. 30 marzo 2010. Rol N 7951-09. "Lagos Araneda, Juan con Subsecretaría de Marina del Ministerio de Defensa Nacional y Caja de Previsión de la Defensa Nacional". Disponible en: http://microjuris.cl/getContent? reference $=\mathrm{MJCH}_{-}$ MJJ23376\&links=[MJJ23376] [fecha de visita 9 de julio de 2016], c. 12º. 
acompaña al desempeño de tales funcionarios. Hay que tener presente que para este autor el concepto de instrumento público abarca distintas modalidades documentales, dentro de las cuales están las leyes, los decretos supremos y las sentencias judiciales ${ }^{29}$. Pues bien, desde su punto de vista la razón que justifica la "plena fe" que la ley atribuye a tales instrumentos (arts. 1700 y $1706 \mathrm{CC}$ ) consiste en la confianza depositada en las actuaciones de los funcionarios públicos, lo cual -en consecuencia- no comprende solo a ministros de fe, sino también a autoridades legislativas, administrativas y judiciales, aun cuando estas no tengan la condición de fedatarios ${ }^{30}$.

Como se ve, esta última es una variante de la perspectiva subjetiva en la que se mezclan los conceptos de fe pública y de función pública. La aplicación de este enfoque implicaría aceptar que la sola presencia de funcionarios públicos competentes es señal de fe pública y que, por lo mismo, su intervención tiene la capacidad de imprimir este atributo a las diversas clases de documentos públicos en cuya confección les corresponde intervenir.

En nuestra opinión, este criterio subjetivo -en sus dos variantesmerece críticas. Primero, porque en materia probatoria el concepto actual de fe pública (y, consecuencialmente, el de documento público) se ha trasladado a un plano preferentemente institucional, más que funcionario; la fe pública proviene no solo de las actuaciones de fedatarios, sino además $-\mathrm{y}$ ante todo- de medidas legales que aseguran la autenticidad documental; el mejor ejemplo es el documento electrónico suscrito mediante firma electrónica avanzada. Segundo, porque para efectos de determinar el valor de la prueba documental pública es indispensable separar las nociones de fe pública y de función pública, tal como lo explicaremos en la última parte del trabajo.

\section{(1.4.) FE PÚBLICA SEGÚN EL CRITERIO PSICOLÓGICO-NATURALISTA}

Este criterio estima que la fe pública es un sentimiento emanado de la sociedad fruto de las necesidades que la vida impone a sus integrantes, de tal suerte que su eficacia no deriva propiamente de la ley ni de los ministros de fe, sino -finalmente- de la convicción social. La fe pública ven-

\footnotetext{
29 Santa Cruz Serrano, Víctor (1941) "El instrumento público”. Revista de Derecho y Jurisprudencia. T. 38, pp. 142-164, p. 143. 
dría a ser una creencia social acerca de la autenticidad y veracidad de los documentos, tanto públicos como privados ${ }^{31}$.

En la doctrina penal, Manzini fue un expositor de este criterio $^{32}$, y en Chile corresponde a la tesis que defendió Cousiño Mac-Iver, al vincular la fe pública con la idea de la "confianza colectiva que se tiene en los documentos, como instrumentos destinados a probar un hecho cualquiera" ${ }^{33}$. Tal confianza la relacionaba específicamente con la fe probatoria que el ente social tiene respecto de los documentos, sean públicos, privados o de comercio; sostenía que frente a una falsificación documental nace el temor de ver extinguido un derecho o alterada gravemente la verdad, lo que produce una desconfianza general por la inseguridad en el documento destinado a probar un derecho o un hecho cualquiera ${ }^{34}$.

Otro autor nacional que aplicó este criterio fue FueYo, para quien la fe pública debía ser concebida como la confianza, creencia y seguridad que entregan determinadas entidades e instrumentos, públicos y privados, que permiten a los particulares mantener a resguardo sus derechos. La fe pública -señalaba- se produce por hechos o antecedentes determinados y calificados, que generan una creencia, estimación, apreciación o persuasión, que a su vez es notoria, manifiesta, divulgada y de conocimiento de todos. Por tal razón, existiría fe pública tanto en un registro público a cargo de un notario, de un conservador de bienes raíces o de otro ministro de fe, como en un registro llevado - con las debidas formalidades- por una sociedad o una entidad privada. Lo realmente importante, concluía Fueyo, es que la colectividad adquiera una confianza y tranquilidad en cuanto a la protección de sus derechos ${ }^{35}$.

Si la concepción subjetiva nos merece críticas por sus restricciones e imprecisiones, las doctrinas precedentes nos generan fuertes resistencias por atentar contra el valor de la seguridad jurídica. Al quedar la fe pública supeditada a las creencias sociales, un documento público podría perder su condición y valor de tal por la sola circunstancia que la sociedad haya perdido la confianza en las autoridades o en las medidas establecidas por el legislador.

\footnotetext{
31 Villacampa (1999) 48-52.

32 Manzini, Vincenzo (1950) Trattato di Diritto Penale italiano. Delitti contro il sentimento religioso e la pietà dei defunti. Delitti contro l'ordine pubblico. Delitti contro la pubblica incolumità. Delitti contro la fede pubblica. Turín: Utet. Vol. 6, 936 pp., pp. 437-591.

33 Cousiño Mac-Iver, Luis (1944) La falsificación de instrumento privado (Ensayo de construcción juridica del delito en Chile). Santiago: Imprenta Stanley, 60 pp., p. 11.

34 Cousiño (1944) i I.

35 Fueyo Laneri, Fernando (1982) Teoría general de los registros. Buenos Aires: Astrea, 248 pp., pp. 20-24, p. 185, pp. 192-197, pp. 238-239; Fueyo Laneri, Fernando (1990) Instituciones de Derecho Civil moderno. Santiago: Editorial Jurídica de Chile, 602 pp., pp. 243-255.
} 


\section{2) NOCIÓN Y CARACTERÍSTICAS DE LA FE PÚBLICA QUE CONCURRE EN LA PRUEBA POR MEDIO DE DOCUMENTOS PÚBLICOS}

\section{(2.1.) Noción}

La fe pública es un elemento de la prueba por medio de documentos públicos, que podemos definir como una institución jurídica compuesta por un conjunto de disposiciones legales cuyo objeto central es garantizar la autenticidad documental. Su fundamento es la seguridad del tráfico jurídico, que en el ámbito probatorio se proyecta a través de normas de valoración legal.

De acuerdo con lo anterior, la fe pública presenta cuatro características: primero, es una institución jurídica; segundo, está integrada por un conjunto de disposiciones legales cuyo objeto central es garantizar la autenticidad de los documentos públicos; tercero, su fundamento es la seguridad del tráfico jurídico y, cuarto, se proyecta en el campo probatorio a través de normas de valoración legal.

\section{(2.2.) FE PÚBLICA COMO INSTITUCIÓN JURÍdica}

\section{(2.2.1.) Explicación}

Cuando afirmamos que la fe pública es una institución jurídica, estamos marcando una separación entre esta noción y los ministros de fe. Pensamos que en la época actual se ha producido un desplazamiento desde las personas de los fedatarios hacia la institución de la fe pública. En la legislación nacional, al menos desde un ángulo probatorio, la fe pública se presenta como una cualidad que se basa en el conjunto de normas legales que permiten garantizar la autenticidad de los documentos, los que en mérito de ello adquieren el carácter de públicos y el valor de tales. Como decíamos, la regulación del documento electrónico suscrito mediante firma electrónica avanzada es la mejor demostración de esta evolución, ya que la autenticidad documental en este caso no se encuentra garantizada por una certificación emanada de un ministro de fe, sino por las diversas medidas de seguridad que rodean a la "firma electrónica avanzada".

En teoría jurídica el vocablo "institución” presenta dos principales acepciones. Ferrajoli explica que en el Derecho las instituciones pueden ser entendidas como ordenamientos o como personas, vale decir, como 
conjunto de normas jurídicas, en un caso, o como sujetos jurídicos capaces de operar dentro del sistema, en otro. Dice este autor que una y otra perspectiva nunca se presentan simultáneamente, sino -en rigor- alternativamente. La primera corresponde a un sistema ordenado de normas, perteneciente a una red objetiva de las relaciones entre actos, situaciones y normas; la segunda se identifica con un aparato organizativo que pertenece a la red intersubjetiva de las relaciones jurídicas entre los sujetos ${ }^{36}$.

La fe pública puede ser calificada como una institución jurídica en el primer sentido, pues lo fundamental es el conjunto de preceptos legales que regula la actividad de confección de documentos. En este sentido, nos inclinamos por definirla siguiendo un criterio publicístico-normativo en una acepción eminentemente objetiva, ya que -repetimos- lo determinante son las normas que regulan el procedimiento de formación de documentos públicos, las que en algunas ocasiones pueden asignar esta función documentadora a determinados organismos o personas que genéricamente reciben el nombre de ministros de fe, y en otras al conjunto ordenado de disposiciones que aseguran la autenticidad documental.

Ante todo, lo que buscamos poner de relieve son las funciones que cumple este elemento (fe pública) en la perspectiva probatoria de los documentos públicos. Más que la presencia de ministros de fe, lo que consideramos fundamental es la existencia de estatutos legales cuyo objeto es regular la formación de documentos a fin de dotarlos de legitimidad en su aspecto externo (autenticidad). Un enfoque similar al que se ha empleado en la ciencia procesal para sostener el carácter institucional del proceso jurisdiccional, entendiéndolo como una creación del Derecho para lograr ciertos fines ${ }^{37}$. En el caso de la fe pública, los fines dicen relación básicamente con la seguridad del tráfico jurídico, lo que en el plano probatorio se vincula ante todo con la autenticidad de los documentos públicos y la valoración legal de estos.

El carácter institucional de la fe pública puede ser vinculado con diversas manifestaciones o aspectos de los documentos públicos. En este lugar destacaremos dos de ellos, que permiten comprender mejor la noción expuesta. El más claro corresponde a la "firma electrónica avanzada"; el segundo, que corresponde al concepto de notaría como "institución" u "oficio", es más tenue, pero de todos modos permite marcar una separación entre la institución de la fe pública y la persona del ministro de fe.

36 Ferrajoli, Luigi (2011) Principia iuris. Teoria del Derecho y de la democracia. 1. Teoría del Derecho. Traducción de Perfecto Andrés Ibáńez et al. Madrid: Trotta, 952 pp., pp. 439-443.

37 Couture, Eduardo J. (1993) Fundamentos del Derecho Procesal Civil. $3^{\text {a }}$ edición. Buenos Aires: Depalma, 524 pp., p. 144. 


\section{(2.2.2.) Documentos electrónicos suscritos mediante "firma electrónica avanzada"}

La firma electrónica avanzada se distingue por la presencia de un "certificado" dado por un "prestador de servicio de certificación acreditado". Según el art. 20 letra b) Ley No 19.799 de 2002, el "certificado de firma electrónica" consiste en una "certificación electrónica que da fe del vínculo entre el firmante o titular del certificado y los datos de creación de la firma electrónica". La letra c) de dicho artículo indica que el "certificador o prestador de servicios de certificación" es aquella "entidad prestadora de servicios de certificación de firmas electrónicas", que para que cumpla con el requisito antes mencionado debe, además, estar "acreditada" en la forma que señalan los arts. 11 inc. $2^{\circ}$ y 17-22 Ley No 19.799 de 2002, y los arts. 13-27 Reglamento No 181/2002 de la Ley No 19.799 de 2002. La letra g) del precitado art. $2^{\circ}$ define la "firma electrónica avanzada" como "aquella certificada por un prestador acreditado, que ha sido creada usando medios que el titular mantiene bajo su exclusivo control, de manera que se vincule unicamente al mismo y a los datos a los que se refiere, permitiendo la detección posterior de cualquier modificación, verificando la identidad del titular e impidiendo que desconozca la integridad del documento y su autoria".

El conjunto de medidas impuestas por las citadas normas y por el resto de las disposiciones legales y reglamentarias, dan lugar a la fe pública institucional a la que nos referimos. La certificación que exigen los preceptos para que estemos frente a una firma electrónica avanzada, es una medida concreta que permite vincular el registro documental con un único sujeto y con los datos contenidos en aquel, sin que pueda desconocerse la autoría ni la integridad del documento. En opinión de SAndoval, la aludida certificación permite resguardar la autenticidad del documento y, a la vez, asegura la confidencialidad y el "no repudio" de la información ${ }^{38}$.

En la doctrina española, Cruz Rivero señala que este tipo de firma electrónica (que en la legislación de España se denomina firma electrónica avanzada reconocida), al contar con un certificado oficialmente reconocido, otorga garantías en cuanto a la autenticidad del documento electrónico y la fidelidad del contenido. Ello permite que el destinatario de un mensaje suscrito con esta clase de firma electrónica pueda estar seguro de que la persona que aparece como firmante de un documento electrónico,

38 Sandoval López, Ricardo (2003) Derecho del comercio electrónico. Santiago: Editorial Jurídica de Chile, 314 pp., pp. 28-30; Sandoval López, Ricardo (2004) Seguridad en el comercio electrónico. Firma electrónica: análisis de la ley $N^{\circ}$ 19.799. Santiago: LexisNexis, 305 pp., pp. 1-13, 91-94. 
es efectivamente el titular de las claves del cifrado y por tanto el suscriptor real del documento. Lo anterior -agrega- cuenta con la garantía de un profesional (el prestador reconocido) que ha asistido al titular de las claves en la salvaguardia de la confidencialidad de la clave privada; además, el sistema de firmado debe reunir requisitos de seguridad adicionales ( $v . g r$. duración, posibilidad de rápida revocación) y una garantía patrimonial que puede responder en caso que se quebrante el sistema por la negligencia de la entidad certificadora, lo que fortalece el valor del registro documental ${ }^{39}$.

Coincidimos con estas apreciaciones. Pensamos que los requisitos antes descritos son fundamentales para resguardar la fidelidad e integridad de los datos que se registran y transmiten por vía electrónica, que es precisamente lo que otorga fe pública a esta modalidad documental. En términos generales, podríamos decir que en el campo de la información electrónica los documentos se prueban a sí mismos (son auténticos per se) gracias a la fidelidad, integridad, confidencialidad y el no repudio de los datos.

En este plano, son especialmente importantes los requisitos impuestos para la operatividad de una firma electrónica avanzada. Nótese que el prestador de servicios de certificación debe estar "acreditado" ante la Subsecretaría de Economía, Fomento y Reconstrucción, para lo cual debe cumplir con todas las exigencias señaladas en los arts. 17-22 Ley No 19.799 de 2002 y en los arts. 13-27 Reglamento No 181/2002 de la Ley No 19.799 de 2002, lo que implica someterse al régimen de fiscalización y responsabilidades previsto en estos preceptos. Este prestador debe, al menos, demostrar a la autoridad la fiabilidad necesaria de sus servicios; garantizar la existencia de un servicio seguro de consulta del registro de certificación emitido; emplear personal calificado; utilizar sistemas y productos confiables; contratar un seguro de responsabilidad civil y, contar con capacidad tecnológica adecuada.

Lo expuesto permite entender por qué el legislador de la Ley $\mathrm{N}^{\circ}$ 19.799 de 2002 efectuó un parangón entre los prestadores de servicios de certificación de firmas electrónicas avanzadas y los notarios. En la historia del establecimiento de este cuerpo legal, se utilizaron expresiones como "notario público electrónico" y "notario virtual", para hacer mención a las funciones que estaban llamadas a cumplir estas entidades ${ }^{40}$. Por nuestra

39 Cruz Rivero, Diego (2006) Eficacia formal y probatoria de la firma electrónica. Madrid: Marcial Pons, 356 pp., pp. 160 y 161.

40 Biblioteca del Congreso Nacional de Chile, Historia de la Ley $N^{\circ} 19.799$, sobre documento electrónico, firma electrónica y los servicios de certificación de dichas firmas, 12 de abril de 2002, pp. 120, 122, 202, 204, 207, 515. 
parte, decimos que aquí existe una concreta manifestación del concepto institucional de la fe pública.

Esta perspectiva institucional aparece recogida en varios preceptos. Uno de ellos es el art. 4º de la Ley No 20.886 de 2015 sobre tramitación electrónica de los procesos jurisdiccionales, en particular el inciso segundo en el que, respecto de las resoluciones judiciales, se sustituye el certificado emanado del ministro de fe por la firma electrónica avanzada: "las resoluciones suscritas por los jueces mediante firma electrónica avanzada, no requerirán de la firma ni de la autorización del ministro de fe correspondiente". Lo mismo explica la modificación introducida al inciso tercero del art. $61 \mathrm{CPC}$, que hasta antes de esta reforma legal giró exclusivamente en torno a los certificados de los fedatarios judiciales; ahora, en cambio, solamente se exige este testimonio en los casos expresamente previstos por la ley, ya que en el resto basta con la firma electrónica avanzada.

\section{(2.2.3.) La notaría como "institución" o como "oficio"}

Otra manifestación de la noción institucional de la fe pública la podemos encontrar en la figura de la notaría entendida como una "institución" o como "oficio". No es tan clara como la anterior, porque la "institución" u "oficio" notarial es un concepto que se relaciona con el segundo aspecto de las instituciones jurídicas, esto es, con los sujetos habilitados para actuar dentro de un sistema. Pero de todos modos contempla una separación entre la institución notarial habilitada para otorgar fe pública a los documentos y la figura del notario como fedatario.

$\mathrm{Al}$ respecto, son atinentes las explicaciones de Romero y MarTínez acerca del sentido que tiene en el Derecho vigente la actividad notarial, en la que lo determinante no es tanto la persona del notario sino la institución de la notaría cuya función es avalar y dar fe de la autenticidad de los actos que se presenten o celebren ante ella. En opinión de estos autores, la notaría constituye lo que en el lenguaje jurídico alemán se denomina "garantía institucional", en el sentido de una institución jurídica cuyo objetivo es garantizar la fe pública ${ }^{41}$.

También es pertinente el razonamiento contenido en la ya citada sentencia de la Corte de Apelaciones de Santiago de 30 de julio de 2008, que al pronunciarse sobre un problema de continuidad laboral de un trabajador de una notaría en la que se produjo el cambio de la persona del

Romero / Martínez (2005) 18 y 19. 
notario, atribuyó a aquella una naturaleza organizacional, la que -a su turno- puede ser vinculada a la noción de institución. Concretamente, señaló que lo relevante "es que se trata de un establecimiento en que se otorgan servicios relacionados con la calidad de ministro de fe pública que tiene el notario; existe una estructura organizacional y el notario público ejerce el poder de dirección de la empresa" ${ }^{42}$.

Como ya lo anticipamos, esta última interpretación no ha sido compartida por la Corte Suprema, bajo el fundamento que dada la regulación que tiene la actividad notarial (los notarios son auxiliares de la administración de justicia) no resulta posible calificar a la notaría como una "empresa” en los términos previstos por la legislación laboral ${ }^{43}$. Igualmente hay que tenerse presente que en algunas de las decisiones de la Corte la noción de notaría, en el fondo, sigue acercándose a la perspectiva institucional al definirla como un "oficio". Así se aprecia en fallos de 14 de junio de 1999 y 5 de julio de $2001^{44}$.

Pues bien, como ha explicado Bravo Lira el sentido propio del "oficio", que proviene de la estructura del Estado indiano de los siglos XVI y XVII, es el de una "institución permanente". Esto significa que constituye una organización que se mantiene jurídicamente idéntica, no obstante la sucesión de sus titulares. A cada oficio corresponde una competencia, con los deberes y derechos consiguientes. Por lo mismo, Bravo Lira señala cuando los juristas de esa época histórica se referían a los deberes y derechos de cada oficio, en rigor estaban describiendo una realidad que solo puede entenderse como una “institución” con un régimen jurídico propio, cualquiera fuere la persona de su titular ${ }^{45}$.

De este modo, al aludir al "oficio notarial", como lo hace la Corte Suprema, o al "establecimiento" dirigido por un notario y al funciona-

42 Corte de Apelaciones de Santiago. Rol No 4149-2007, c. $1^{\circ}$.

43 Por ejemplo: Corte Suprema. 14 de junio de 1999. "Aguilar Rosas, Óscar y otros con Yaber Simon, Sergio". Revista de Derecho y Jurisprudencia. T. 96, sec. 3a , pp. 98-109, cs. 1, 2o y $3^{\circ}$ de la sentencia de reemplazo, p. 101; Corte Suprema. 19 de enero de 2000. "Chaur Monsalve, Sabina y otros con Bambach Echazarreta, José”. Revista de Derecho y Jurisprudencia. T. 97, sec. 3a, pp. 20-24, c. 5o, pp. 21 y 22; Corte Suprema. 5 de julio de 2001. "Cona Quijada, Alejandra con Ramdohr Janssen, Carlos". Revista de Derecho y Jurisprudencia. T. 98, sec. 3a , pp. 137-141, cs. 8º y 9o, p. 140; Corte Suprema. 17 de agosto de 2006. "Hinostroza Sepúlveda, Teresa Susana y otros con Sucesión Vega Varas, Guillermo". Revista de Derecho y Jurisprudencia. T. 103, sec. 3a, pp. 872-877, c. 5º, pp. 874 y 875.

44 CS. 14 junio 1999 , c. $2^{\circ}$ de la sentencia de reemplazo, p. 101 ; CS. 5 julio 2001. c. 9o, p. 140.

45 Bravo Lira, Bernardino (2009) "Oficio y oficina, dos etapas en la historia del Estado indiano”. En El juez entre el Derecho y la ley, en el mundo hispánico. Del Estado de Derecho al Derecho del Estado (siglos XVI a XXI). 2a edición. Santiago: LegalPublishing, pp. 129-163, pp. 136-138. 
miento de "una estructura organizacional" regulada por el ordenamiento legal, como lo hizo la Corte de Apelaciones de Santiago, lo que se hace -a fin de cuentas- es tratar a la notaría como institución jurídica. Ello, a su vez, implica ubicar la noción de fe pública en el plano que comentamos.

\section{(2.3.) LA FE PÚBlica SE COMPONE DE UN CONJUNTO DE DISPOSICIONES LEGALES CUYO OBJETO CENTRAL ES GARANTIZAR LA AUTENTICIDAD DE LOS DOCUMENTOS PÚBLICOS}

Según lo indicado, el núcleo conceptual de la fe pública está compuesto por las normas legales que regulan la actividad de confección de documentos públicos. Esta regulación conforma un procedimiento legal especial cuyo objeto es la generación de documentos revestidos de garantías suficientes para dar por establecida su autenticidad. De esta manera, para fines probatorios la fe pública se presenta como una institución orientada a asegurar la autenticidad de los documentos públicos.

A diferencia de lo que sucede en materia penal, donde los conceptos de fe pública, autenticidad documental y veracidad del contenido documental tienen importancia para los fines de determinar la protección de bienes jurídicos en los delitos de falsedades documentales ${ }^{46}$, lo relevante en el ámbito probatorio es la garantía de genuinidad del documento público como continente de información fáctica. En otras palabras, lo importante es que el documento público dotado de fe pública es auténtico en sí mismo gracias al conjunto de normas que regulan su proceso de confección y, con ello, aseguran su legitimidad externa (autenticidad), compuesta por la autoría, data e integridad del documento. "Acta probant se ipsa", como se señalaba en la antigua doctrina francesa ${ }^{47}$. "El instrumento público da por sí mismo plena prueba de su autenticidad, en el sentido de que se reputa emanar el notario o funcionario público que aparece en él autorizándolo", como afirmaba Claro Solar al comentar el art. $1700 \mathrm{CC}^{48}$.

El documento público investido de fe pública se prueba a sí mismo, lo que quiere decir que es autárquico o autosuficiente en cuanto conti-

Bonnier, Eduardo (1929) Tratado teórico y práctico de las pruebas en Derecho Civil y en Derecho Penal. Traducción de José de Vicente y Caravantes. $5^{\text {a }}$ edición, Madrid: Reus. T. II, 676 pp., pp. 23 y 24.

48 Claro Solar (1992) 675.
} 
nente de información fáctica; y como tal, puede ser usado como fuente de prueba (en sede extrajudicial) y como medio de prueba (en el proceso jurisdiccional), sin necesidad de acreditar en forma previa su autenticidad ${ }^{49}$. Hay que tener presente que un documento solamente tendrá valor como evidencia judicial en la medida que se encuentre comprobada su autenticidad. Lo primero que debe hacer el juez al estudiar el mérito probatorio de un documento es determinar si está o no acreditada su autenticidad, para luego establecer su valor en cuanto a la veracidad de la información almacenada en él. Un documento inauténtico carece de toda fuerza probatoria, pues carece de legitimidad como registro de información sobre hechos; los penalistas señalan que se trata de un documento que no existe como tal ${ }^{50}$. Un documento auténtico tiene valor como continente de información fáctica, cuya suficiencia para dar por comprobados los hechos discutidos en un proceso deberá ser evaluada de acuerdo con el sistema de apreciación aplicable. Como ha señalado la jurisprudencia española, una cosa es la autenticidad de un documento (legitimidad del continente) y otra la eficacia probatoria para demostrar los hechos de la causa ${ }^{51}$.

Pues bien, una de las características que presentan los documentos públicos dotados de fe pública es que su autenticidad se encuentra demostrada desde que son confeccionados en virtud de las garantías que conceden las normas que regulan las actividades de confección de los mismos. En la doctrina notarial, esta regulación recibe el nombre de "proceso notarial" 52 , "procedimiento notarial" 53 o "rito instrumental" 54 . De esta manera se alude a la sucesión reglada de actuaciones que deben desarrollarse al interior del notariado para elaborar documentos públicos. Como explicó Núñez Lagos, tales documentos públicos son el resultado de la

49 Serra Domínguez, Manuel (2009) "Prueba documental". En Estudios de Derecho Procesal. Lima: Communitas, pp. 201-248, p. 231; Montero Aroca (2012) 319.

50 Rojas Aguirre (2014 a) 545-551.

51 Montero Aroca (2012) 316 y 317, np. 34, citando una sentencia de 25 de noviembre de 2002 del Tribunal Supremo español.

52 Etchegaray, Natalio Pedro (2010) Escrituras y actas notariales. $5^{\text {a }}$ edición. Buenos Aires: Astrea, 359 pp., p. 35.

53 Cruz Barrios, Norman (1973) Derecho notarial chileno. La función notarial y el instrumento público, en especial la escritura pública. Teoría, doctrina, legislación y jurisprudencia. Santiago: López-Vianco, 327 pp., pp. 110-113; Vidal Domínguez (1997) 145.

54 González, Carlos Emérito (1953) Teoría general del instrumento público (Introducción al Derecho notarial argentino y comparado). Buenos Aires: Ediar, 475 pp., p. 123; Pelosi, Carlos A. (2006) El documento notarial. 4a reimpresión. Buenos Aires: Astrea, 349 pp., pp. 179-181. 
aplicación de una serie de actos y formalidades establecidos por el Derecho Notarial ${ }^{55}$.

La necesidad de contar con estatutos legales expresos y especiales tiene importancia en tres principales aspectos. Por una parte, constituye la base del sistema de garantías que rodea a la fe pública, a partir del cual es posible dar por acreditada la autenticidad de los documentos públicos. Por otra, permite descartar la teoría psicológica-naturalista de la fe pública, al quedar sometida a la potestad del legislador y no a las creencias sociales. Por último, permite establecer una diferencia entre estos documentos públicos y aquellos que son el resultado del ejercicio de funciones públicas, al menos en lo que respecta al valor probatorio.

Rivacoba sostenía -con acierto- que la fe pública es "la confianza generalizada en la autenticidad y el valor de ciertos objetos, signos o documentos que suscita o impone la garantía que les dispensa el Estado, sea directamente o a través de instituciones o los funcionarios o ministros en quienes delega al efecto" 56 . Explicando esta definición, precisaba que aunque en la realidad de los hechos la confianza no se puede imponer (la confianza -decía Rivacoba- es espontánea o no es confianza, sino desconfianza), en el mundo jurídico, que es eminentemente formalista, es frecuente prescribir una conducta determinada a los individuos "como si abrigasen cierta confianza y obraran en su virtud" 57 .

La Corte Suprema, en la citada sentencia de 30 de enero de 2012, enfatizó estos puntos al momento de interpretar el art. 434 No 4 inc. $2^{\circ}$ CPC y a la frase contenida en él ("cuya firma aparezca autorizada por un notario"), en relación con los arts. 401 No 10 y 425 COT $^{58}$. En concepto de la Corte, la fe pública consiste en la autoridad legítima atribuida a los notarios "para que los documentos que autorizan en debida forma sean considerados como auténticos y lo contenido en ellos sea tenido por verdadero mientras no se haga prueba en contrario" (c. 6०). Existe "un supuesto de virtuosismo en el ejercicio de la función notarial, en la medida que tales definiciones [de fe pública] trasuntan la idea según la cual en la condición del notario está insita la veracidad de lo que hace. Si no fuera así, lo suyo no estaría revestido de la fuerza de la legitimidad, de la autenticidad y de la veracidad que, al menos en lo que va del análisis, indudablemente se le atribuye" (c. $8^{\circ}$ ). Podría ser, ańade la sentencia, que "en estos tiempos un concepto seme-

\footnotetext{
55 NúŃEz Lagos, Rafael (1986 d) "El Derecho Notarial”. Estudios de Derecho Notarial. Madrid: Instituto de España. T. I, pp. 1-47, pp. 15-16.

Rivacoba (I986) 44.

Rivacoba (1986) 44.

CS. Rol No $12716-2011$, cs. 50-11\%.
} 
jante fuese mirado como exagerado, extremo, demasiado absoluto. Empero, no es esa sensación de mayor o menor desconfianza popular en determinados cometidos públicos la que haya de servir de parámetro para la resolución de lo pendiente. Esto exige buscar en el ordenamiento alguna luz que conduzca a la aprobación o desaprobación de la tesis que viene de presentarse, es decir, que la ejecutividad de un documento de aquellos a que se refiere el [art. $434 N^{\circ} 4$ inc. $\left.2^{\circ} \mathrm{CPC}\right]$ no hace indispensable que el obligado lo rubrique en presencia física del notario ni que este deje en él estampada las razones a base de las cuales da fe de la identidad" (c. 80).

En relación con el mismo tema, también son pertinentes las conclusiones expuestas por la Corte Suprema mediante sentencia de 17 de julio de 2014, que su motivación $7^{\text {a }}$ señala que el sentido de la norma es claro: "el concepto 'autorización notarial' debe ser entendido en su sentido procesal, como palabra técnica, conforme al [art. 21 CC] y, desde ese punto de vista, la expresión denota la legalización que pone el escribano en alguna escritura o instrumento, de forma que haga fe pública, esto es, atestando la verdad de las firmas puestas en él. El vocablo 'autorizar' no supone, necesariamente, la presencia de la persona cuya rúbrica autentifica y, por consiguiente, la correcta interpretación del [art. $434 N^{\circ} 2$ inc. $2^{\circ}$ CPC] ni siquiera lleva a exigir la comparecencia ante el notario del obligado que firma un instrumento mercantil, sea pagaré, cheque o letra de cambio, bastando al efecto la sola actuación del ministro de fe autorizante y la circunstancia de que a este último le conste la autenticidad de la firma que autoriza" 59.

\section{(2.4.) LA FE PÚbliCA TIENE COMO FUNDAMENTO LA SEGURIDAD DEL TRÁFICO JURÍDICO}

La fe pública garantiza la autenticidad de los documentos públicos y con ello otorga seguridad al tráfico jurídico. Por lo mismo, podemos decir que esta institución tiene como fundamento la seguridad de las relaciones y situaciones jurídicas cuyo núcleo básico es la autenticidad documental. Los operadores del sistema tienen mayores seguridades en el tráfico, cuando concurren garantías en cuanto a la legitimidad del documento público como tal, esto es, a su genuinidad y autosuficiencia como elemento probatorio.

59 CS. Rol No 7240-2014, c. 7o. También puede consultarse las siguientes sentencias que reproducen este razonamiento: CS. Rol No 13.148-2013, c. 6; C. Ap. Santiago. Rol No 7891-2015, cs. 5 y 6o; C. Ap. Santiago. Rol No 7709-2015, c. 5º 
Esto ha sido destacado por ETCHEBERRY entre los penalistas, cuando afirma que para fines punitivos la fe pública debe ser entendida como la seguridad del tráfico jurídico que se obtiene a través de documentos públicos en virtud de expresas previsiones legales. Señala que los casos regulados en el Título IV del Libro II del Código Penal se caracterizan por tratarse de objetos que la ley ha ligado a ciertos efectos jurídicos de obligatoriedad general, efectos que en la situación de los documentos públicos dicen relación fundamentalmente con la autenticidad y valor probatorio seńalado por la ley. A falta de mejor denominación, sostiene que puede llamarse tráfico jurídico al conjunto de relaciones que nacen al amparo del orden legal y que desenvuelven armoniosa y pacíficamente gracias a la eficacia de los símbolos materiales autenticados ${ }^{60}$.

De esta manera, Etcheberry plantea una conexión entre la fe pública, las disposiciones legales que asignan autenticidad a los documentos públicos y la seguridad de las relaciones jurídicas desarrolladas en sociedad. La fe pública viene a ser, así, un atributo incorporado a los documentos públicos que deriva de una serie de resguardos establecidos por el ordenamiento legal con miras a garantizar el correcto desenvolvimiento del tráfico. Gallegos coincide con esta apreciación, y -en lo medulartambién lo hacen Garrido Montt, y Politoff, Matus y Ramírez ${ }^{61}$. Estos últimos autores añaden una referencia especial a la función probatoria de los documentos públicos que resulta coincidente con lo que hemos indicado, en especial cuando expresan que la fe pública lesionada con las falsificaciones, regulada por el art. $193 \mathrm{CP}$, ha de relacionarse con "la fiabilidad, la seguridad del tráfico jurídico, en particular el valor probatorio" de aquella clase documental ${ }^{62}$.

En la misma dirección, mediante sentencia de 3 de mayo de 1996, la Corte de Apelaciones de San Miguel sostuvo que la fe pública "se identifica por la doctrina penal moderna con la seguridad y normalidad del tráfico jurídico, concepto este que se halla ligado estrechamente a la autenticidad de determinados elementos a los cuales la ley ha atribuido ciertos efectos juridicos de obligatoriedad general, en especial, la producción de confianza en la genuinidad de ellos" 63 .

Otros penalistas han utilizado similares nociones pero con otros enfoques. En España, por ejemplo, Villacampa sostiene que el objeto ju-

\footnotetext{
60 Etcheberry (I96i) 56-62; Etcheberry (1998) 136.

61 Gallegos (2000) 103-104; Garrido Montt (2008) 14; Politoff/ Matus/ Ramírez (2011) 555 .

62 Politoff/ Matus/ Ramírez (20 I i) 555.

63 C. De Ap. San Miguel. 3 mayo 1996. c. 9o, p. 154.
} 
rídico protegido por los delitos de falsedades documentales es el correcto funcionamiento del tráfico negocial y, más en particular, la confianza en el mismo, lo que tiene impacto en las funciones de garantía, de perpetuación y de prueba que cumple el documento. La función de garantía, indica esta autora, supone la recognoscibilidad en el documento de la persona a la que se imputa la declaración documentada; la de perpetuación consiste en la cualidad que tiene el documento para fijar en el tiempo una declaración sobre un soporte perdurable; la función probatoria se traduce en la aptitud del documento para constituir un medio de prueba ${ }^{64}$. Por su parte, Rojas Aguirre sostiene que en las falsedades documentales el fin de protección de las normas penales es siempre la autenticidad del documento, ya que lo básico para que este cumpla sus funciones en el tráfico jurídico es que exista como tal (que sea auténtico). Agrega que en algunos casos el fin de protección será, además, la verdad del contenido documental, lo que en su opinión ocurre cuando estamos frente a documentos públicos testimoniales, en los que el respectivo funcionario deja constancia de hechos que ha percibido ${ }^{65}$. En fin, MaYer y Vera destacan la relevancia que ha tenido durante la historia del Derecho Penal la protección de la autenticidad y veracidad de los documentos (sobre todo los públicos), precisamente para la seguridad jurídica de las relaciones entre las personas ${ }^{66}$.

Con independencia de la denominación que se asigne al elemento que estudiamos, lo cierto es que los documentos públicos presentan una característica que en el plano de las pruebas los diferencia de los documentos privados, y que consiste en la capacidad para demostrar por sí mismos su autenticidad ${ }^{67}$. Tratándose del elemento que estudiamos (que para mejor comprensión preferimos seguir llamando fe pública), esta demostración tiene mayor fuerza probatoria precisamente a raíz de las medidas que rodean al proceso de confección documental, que garantizan su autenticidad.

64 Villacampa (I 999) 91-95. Con un planteamiento similar, en la doctrina nacional: Rodríguez Collao / Vera (2004) 130-135; Vargas (2013) 125-135.

65 Rojas Aguirre (2014 a) 545-551; Rojas Aguirre (2015) 155-165.

66 Mayer Lux, Laura; Vera Vega, Jaime (2015) "Historia del objeto material del delito de falsedad documental punible". Revista de Estudios Histórico-Jurídicos. Pontificia Universidad Católica de Valparaíso. No 37, pp. 325-346.

67 Claro Solar (1992) 675-682; Santa Cruz (1942) 22, 35; C. Ap. Santiago. 26 mayo 1981, c. 6o , p. 68; Corte Suprema. 11 de agosto de 2004. "Universidad de Concepción con Comercial Eccsa S.A.". Revista de Derecho y Jurisprudencia. T. 101, sec. 1ª, pp. 216-220, c. $12^{\circ}$, p. 219 . 


\section{(2.5.) LA FE PÚBLICA SE PROYECTA EN EL CAMPO PROBATORIO A TRAVÉS DE NORMAS DE VALORACIÓN LEGAL DE LOS DOCUMENTOS PÚBLICOS}

La seguridad del tráfico jurídico se proyecta a través de un sistema de valoración en el que el legislador determina el grado de eficacia probatoria de los documentos públicos dotados de fe pública. Núñez Lagos decía que la fe pública consiste en un valor del documento público en sí mismo, que da lugar a una prueba legal y, a su vez, permite asegurar el desenvolvimiento de las relaciones jurídicas ${ }^{68}$. En similar sentido, RodRíGuez Adrados sostiene que la fe pública es una fe garantizada por el ordenamiento y necesaria para la seguridad jurídica: "a falta de fe pública, pues, más pleitos, y de resultados más inciertos; y freno al desarrollo económico que exige soluciones rápidas y seguras". En su opinión, en el plano probatorio lo anterior conduce a un sistema de valoración legal ${ }^{69}$.

Así, en aras de la seguridad del tráfico jurídico los documentos públicos investidos de fe pública deben ser tratadas como evidencias sometidas a un sistema legal de valoración, que, por ende, constituyen una excepción al método judicial de apreciación según las reglas de la sana crítica (u otro equivalente, como la denominada "valoración en conciencia"). Sobre el particular existe una importante coincidencia de opiniones en la doctrina procesal nacional y extranjera ${ }^{70}$.

En concordancia con lo dicho, la valoración legal de esta prueba se concentra en la autenticidad de los documentos públicos, ya que el conjunto de garantías inherentes a la fe pública apunta a la dimensión externa de aquellos. Como explicaba Serra Domínguez, la importancia y utilidad del documento público consiste precisamente en acreditar en forma indiscutible la autoría y fecha del documento, así como todas las circunstancias que han contribuido a su formación, lo que -en su opinión- se logra a través de la intervención de ministros de fe que otorgan fe pública sobre tales puntos ${ }^{71}$. En relación con los instrumentos públicos y la regla del art. 1700 CC, SANTA Cruz sostuvo que este documen-

68 NúŃEZ LAGOS (1986 a) 333.

69 Rodríguez Adrados (I996) 176.

70 Destacamos: Calvo Castro, Gonzalo (198I) "Sistemas de apreciación de la prueba". En: Rudolffi Dunlop, S. (coordinador). Nuevas orientaciones de la prueba. Santiago: Editorial Jurídica de Chile, pp. 133-155, pp. 153-154; Couture (i989) 120; Serra Domínguez (2009) 206-209, 215-218, 240-242; Bonet Navarro, José (2009) La prueba en el proceso civil. Cuestiones fundamentales. Madrid: Difusión Jurídica, 361 pp., pp. 240-243; Montero Aroca (201 2) 319-323, 598-600.

71 Serra Domínguez (2009) 215 y 216. 
to hace plena fe entre las partes y respecto de terceros en todo lo que el funcionario certifica atendida la fe pública de la que está revestido, lo que genera efectos respecto de todos y permite dar por probada su autenticidad $^{72}$.

Esto, sin embargo, no impide que el legislador también le asigne valor probatorio al contenido de estos documentos, ya que las propias características de la fe pública permiten justificar reglas legales respecto de la veracidad de los hechos registrados en ellos. Siendo un problema de axiología jurídica en el campo de las pruebas, la solución dependerá de las opciones o preferencias en cada ordenamiento. De todos modos, la simple referencia a un sistema legal de valoración probatoria requiere precisiones y matices, pues no existe una única forma de intervenir normativamente en la actividad de apreciación judicial de las probanzas.

Todo este análisis excede los límites del trabajo, sin perjuicio de lo cual podemos señalar que fe pública posee la capacidad para servir de fundamento a un sistema de tarifa legal como el consagrado en los arts. 1700 y 1706 CC. Vale decir, un sistema en el que el legislador determina derechamente la suficiencia de un medio de prueba para dar por establecido un hecho, sin necesidad de la concurrencia de otras probanzas. Estimamos que la fe pública es la única institución jurídica en materia de prueba documental pública que justifica la dictación de normas de tarifa legal, las que incluso pueden recaer sobre la veracidad de la información almacenada en los documentos, como sucede con las dos normas civiles que acabamos de citar.

Los preceptos de tarifa legal constituyen la técnica jurídica de valoración más intensa que consagra el ordenamiento nacional, que establece soluciones normativas en la determinación de las cuestiones de hecho que solo pueden ser desvirtuadas por medio de un procedimiento judicial de impugnación u objeción. Tratándose de los documentos públicos, lo anterior implica que respecto de los extremos cubiertos por estas normas (autenticidad y, en algunos aspectos, veracidad), los tribunales tienen el deber de asignar suficiencia a estas probanzas y, por ende, tienen que dar por comprobadas las respectivas cuestiones de hecho. En un proceso civil y a falta de normas que establezca otra solución, los jueces solo podrán concluir lo contrario en la medida que la parte afectada haya formulado el correspondiente procedimiento de objeción documental y haya acre- 
ditado satisfactoriamente el motivo de la impugnación (por nulidad del documento público, falta de autenticidad o falta de veracidad $)^{73}$.

Esto permite trazar una línea divisoria entre las distintas clases de documentos públicos, dado que en el ámbito de la valoración probatoria el modelo de más elevado grado de fuerza normativa es el de tarifa legal. Estimamos, así, que atendidas las mayores seguridades que rodean a la fe pública, solamente los documentos públicos dotados de esta especial cualidad admiten la aplicación de un estatuto legal tasado. Esto explica la existencia de los arts. 1700 y 1706 CC, establecidas específica y exclusivamente para los instrumentos públicos y las escrituras públicas, que son documentos revestidos de fe pública.

Las demás documentaciones dotadas de fe pública tendrán otro tipo de técnica de valoración legal (por vía de presunciones legales o de regulación del onus probandi). No es el lugar para profundizar sobre el punto, salvo en lo que respecta a la diferencia con los documentos públicos que son creados con motivo del ejercicio de funciones públicas y que no cuentan con fe pública, a los que nos referiremos a continuación.

\section{3) DOCUMENTOS PÚBLICOS QUE SON CONFECCIONADOS DURANTE EL EJERCICIO DE FUNCIONES PÚBLICAS (“DOCUMENTOS OFICIALES”)}

\section{(3.1.) Planteamiento}

Como dijimos, las nociones de fe pública y de función pública deben ser separadas a los fines de determinar el valor probatorio de los documentos públicos. No cabe asignar equivalencia entre ambas ni siquiera en aquellos casos en que un texto legal califica como "ministros de fe" a funcionarios públicos que desarrollan actividades de inspección o fiscalización, pero que no reúnen las condiciones básicas que definen a esta institución jurídica que llamamos fe pública. No basta con que la ley asigne a un determinado funcionario la calidad de fedatario para que el documento que elabore tenga este atributo.

De acuerdo con lo que explicamos antes, en la prueba documental pública solo podemos hablar de fe pública cuando la ley regula de modo concreto y especial el procedimiento de elaboración de documentos, adoptando medidas tendientes a garantizar su autenticidad. Esto no tiene

\footnotetext{
73 Como marco referencial para comprender esta técnica de valoración legal que llamamos tarifa legal, véase Liebman, Enrico Tullio (1980) Manual de Derecho Procesal Civil. Traducción de S. Sentís Melendo. Buenos Aires: Ejea, pp. 315-317.
} 
lugar en los documentos que son confeccionados durante el ejercicio de funciones públicas, que en Chile suelen ser identificados como "documentos oficiales" (art. 193 No 8 CP). En nuestro parecer, estos documentos también deben ser tratados como pruebas documentales públicas y, como tales, como pruebas con valoración legal, pero con un grado de eficacia menor del que corresponde a los documentos dotados de fe pública.

Hay que advertir que el significado de esta categoría documental (los documentos oficiales) ha generado discusión entre los autores. Recientemente, MaYer y Vera han concluido, con buenos argumentos, que para efectos de los delitos de falsedad documental estos documentos admiten la calificación de públicos ${ }^{74}$. Compartimos esta doctrina. Desde un punto de vista probatorio, esta clase documental presenta una característica común con los documentos públicos dotados de fe pública, que permite diferenciarlos de los documentos privados y considerarlos pruebas documentales públicas. Nos referimos a la capacidad para probar por sí mismos su autenticidad. Los documentos oficiales, por el hecho de ser generados durante el ejercicio de funciones públicas, con debido cumplimiento de exigencias orgánicas y formales, poseen una serie de características externas (sellos, timbres u otras) que demuestran su autenticidad, siendo innecesaria a su respecto la prueba complementaria que sí se requiere para los documentos privados (art. 346 CPC). Existe jurisprudencia en este sentido ${ }^{75}$.

\section{(3.2.) IDENTIFICACIÓN DE LOS CONCEPTOS DE FE PÚBLICA Y FUNCIÓN PÚBLICA EN LA DOCTRINA Y JURISPRUDENCIA CHILENAS}

En la doctrina y la jurisprudencia chilenas, la distinción entre fe pública y función pública no ha estado del todo presente.

Santa Cruz y Moreno Vaccaro estimaban que la actividad desarrollada por los funcionarios públicos había que considerarla equivalente al otorgamiento de fe pública. Por esta razón, ambos autores pensaban que los documentos elaborados por organismos y empleados públicos de-

74 Mayer Lux, Laura; Vera Vega, Jaime (2016) "El concepto de documento público y de documento oficial para efectos de los delitos de falsedad documental: consideraciones histórico-dogmáticas para su determinación". En Cárdenas Aravena, C.; Ferdman Niedmann, J. (coordinadores). El Derecho Penal como teoría y como práctica. Libro en homenaje a Alfredo Etcheberry Orthusteguy. Santiago: Thomson Reuters, pp. 752-776, pp. 751-773.

75 Por ejemplo: CS. 11 agosto 2004, c. 12º, p. 219; Corte de Apelaciones de Santiago. 20 de marzo de 1998. "Abumohor Raposo, Leila con Fisco". Revista de Derecho y Jurisprudencia. T. 95, sec. 2a, pp. 20-26, c. I, p. 23. 
bían tener el valor probatorio previsto por los arts. 1700 y 1706 CC, esto es, debían "hacer fe" en cuanto a su autenticidad y veracidad"

La Corte Suprema mediante sentencias de 22 de enero de 2008 y 15 de julio de 2009, y la Corte de Apelaciones de Rancagua en fallo de 24 febrero de 2011, han concluido que los tipos penales de falsificación de documentos públicos incluyen los casos de documentos oficiales, ya que estos emanan de funcionarios públicos que -a su turno- deben ser considerados depositarios de fe pública ${ }^{77}$.

El fallo de 15 julio 2009 es el más explícito en el sentido que comentamos. Al analizar la naturaleza de los permisos de circulación vehicular y el efecto que genera la intervención de un funcionario municipal en su otorgamiento, la Corte Suprema señaló lo siguiente: "desde esa perspectiva resulta innegable que el permiso de circulación vehicular aun cuando da cuenta del pago del impuesto correspondiente a una categoría determinada y que por mandato legal debe ser emitido por el Director de Tránsito de la Municipalidad en que se obtiene, constituye un documento oficial y por ende público, toda vez que proviene de un organismo público y como tal está bajo la custodia de un funcionario municipal en razón de su cargo, quien por eso mismo y en su carácter de depositario de la fe pública, está obligado a consignar la verdad al extenderlo"78.

\section{(3.3.) La tesis de Parejo en la doctrina española}

En la doctrina administrativista espańola, Parejo ha sostenido que la fe pública debe ser calificada como una actividad o función pública, de lo cual correspondería concluir que todas las documentaciones elaboradas en el campo administrativo estarían acompañadas de tal atributo ${ }^{79}$. En la base de esta doctrina se encuentran las nociones de confianza y

76 Santa Cruz (i 942) 6; Moreno Vaccaro, Rubén (1957) Los documentos oficiales. Santiago: Editorial Universitaria, 133 p., pp. 71-75.

77 Corte Suprema. 22 de enero de 2008. Rol No 4960-07, “contra Cáceres Ahuad, Carlos". Disponible en: http://microjuris.cl/getContent?reference $=\mathrm{MJCH}$ MJJ16674\&links=[MJJ16674] [fecha de visita 9 de julio de 2016], cs. 3o y 7o; CorTE Suprema. 15 de julio de 2009. Rol No 2924-08. "Barroso Barroso, María con Manterola Delgado, Carlos". Disponible en: http://microjuris.cl/getContent?reference=MJCH_ MJJ20453\&links=[MJJ20453] [fecha de visita 9 de julio de 2016], c. 10;

Corte de Apelaciones de Rancagua. 24 de febrero de 2011. Rol No 25-09, "contra Bravo Lobos, María Lorena y otros". Disponible en: http://microjuris.cl/ getContent?reference=MJCH_MJJ26521\&links=[MJJ26521] [fecha de visita 9 de julio de 2016], c. $2^{\circ}$.

78 CS. Rol No 2924-08, c. $1^{\circ}$

79 Parejo Alfonso, Luciano (I 994) “Fe pública y administración pública”. En AA. VV. La fe pública. Madrid: Colegios Notariales de Espańa, pp. 155-189, pp. 163-168. 
seguridad jurídica, que a juicio de este autor resultan aplicables a los actos y relaciones de Derecho Privado y Público. Ambos conceptos -agrega- reconducen a la fe pública que, bajo ciertos requisitos, acompaña a determinados negocios jurídicos privados y a todas las actuaciones de los órganos públicos.

Indica Parejo que el correcto funcionamiento del tráfico privado y de la gestión pública, así como la estabilidad de los derechos, relaciones y situaciones generadas en cada esfera, exigen que no se pongan en duda y no se cuestionen tales derechos, relaciones y situaciones. Se necesita una confianza en el reconocimiento de los actos y negocios y, por ende, una seguridad jurídica mínima en cuanto a su existencia, contenido y consecuencias. Todo ello, a su turno, se conecta con la figura llamada fe pública. "A este fin sirve la fe pública, que obviamente es un valor cuyo radio de acción alcanza a la totalidad del ordenamiento jurídico. Quiere esto decir que la necesidad a que responde y el criterio estimativo que expresa operan igualmente en las relaciones jurídicas privadas y en las públicas, en el tráfico social de los sujetos comunes y en el propio y específico de los sujetos singulares o poderes públicos" 80 .

La fe pública, expone Parejo, siempre se presenta como una actividad pública orientada a entregar esa confianza y seguridad. Cuando se trata de actos privados, interviene a través de un ministro de fe (el notario), a quien la ley le atribuye expresamente la función de certificar la efectividad de determinadas circunstancias relacionadas con esa clase de negocios jurídicos. Señala que esta fe pública está enderezada fundamentalmente a hacer prueba, y así generar confianza y seguridad en el tráfico.

En cambio, cuando se trata de actuaciones de órganos públicos y, más particularmente, de actos de la Administración del Estado, no es menester que intervenga un funcionario especial, puesto que en opinión de este autor la fe pública se encuentra incorporada en el propio ejercicio de funciones públicas. En el tráfico de la Administración Pública, señala Parejo, "la fe pública, aparece, como regla general, subsumida en el ejercicio de las potestades y de las competencias en que estas se desagregan por los distintos órganos administrativos, en calidad de uno o más de los elementos de la forma de los actos en que dicho ejercicio se traduzca" 81 .

En definitiva, lo que sostiene este autor es que el conjunto de elementos objetivos y formales que rodean al ejercicio de las funciones públicas (y, particularmente, de las administrativas), serían constitutivos de

\footnotetext{
80 PAREJO (I994) 161.

81 Parejo (I994) 168
} 
fe pública. Por eso la referencia a las formas de los actos administrativos, que a diferencia de lo que ocurre con los actos y contratos privados, en el caso de la gestión pública-administrativa es esencial. La actuación pública -afirma- siempre es formalizada, sea unilateral o bilateral o multilateral, y se construye dogmáticamente mediante una doble reducción, paralela a la propia del Derecho Privado, en formas jurídicas de actuación y, consecuentemente, en negocios jurídicos típicos ${ }^{82}$.

\section{4) NECESIDAD DE DISTINGUIR LA FE PÚBLICA Y LA FUNCIÓN PÚBLICA COMO ELEMENTOS DE LA PRUEBA POR MEDIO DE DOCUMENTOS PÚBLICOS}

\section{(4.1.) ALGUNOS ANTECEDENTES HISTÓRICOS Y COMPARADOS}

La distinción que planteamos tiene base en la tradición jurídica de la cual proviene la legislación nacional sobre documentos públicos, en particular las Siete Partidas en la cual se atribuyó diferente significado probatorio a estas dos modalidades documentales (las investidas de fe pública y las que son el resultado de ejercicio de funciones públicas) ${ }^{83}$. Esta separación se realizó a partir de la regulación de dos figuras: los "instrumentos publicos" y las "cartas selladas".

En las Leyes 114 y 115 de la Partida 3a, Título 18, se estableció que los "instrumentos publicos" debían ser creídos por el juez en todo lo que en ellos aparecía escrito; en cambio, las "cartas selladas" únicamente hacían prueba en contra de su autor ${ }^{84}$. La mayor fuerza de la primera modalidad documental se encuentra directamente asociada a la mayor rigurosidad de las exigencias formales a las que estaban sometida y la investidura que se atribuía a los escribanos (antecesores de los notarios). Hay que decir que en esta legislación los escribanos eran tratados como "personas públicas" y

\footnotetext{
82 PAREjo (I994) 171-172.

83 Cabe tener presente que las normas de las Siete Partidas no solo influyeron en la regulación de los documentos públicos (en especial, los notariales), sino que además rigieron como Derecho positivo hasta el año 1925, cuando entró en vigencia el llamado "Código del Notariado" (DL No 407 de 1925). Sobre la influencia y la aplicación de esta regulación, pueden consultarse: Lazo, Santiago (1936) Los códigos chilenos anotados. Del Notariado. Legislación y jurisprudencia. Santiago: Imprenta y Litografía La Ilustración, 139 pp., pp. 3, 4 y 111; LirA, José Bernardo (1880) Prontuario de los juicios. $3^{\text {a }}$ edición. Santiago: Imprenta de "el correo". T. I, 432 pp., p. 50.

84 Las Siete Partidas del Sabio Rey don Alfonso el IX, glosadas por el Licenciado Gregorio López, del Consejo Real de Indias de S.M., Oficina de D. León Amarita, Madrid, 1829. T. II, pp. 311-316.
} 
"testigos públicos" cualificados ${ }^{85}$, a quienes la ley reconocía la legítima y excluyente potestad para formalizar actos y negocios jurídicos privados y dotarlos de fe pública ${ }^{86}$.

Las "cartas selladas", si bien provenían de personas investidas de autoridad y crédito (eran calificadas como personas "auténticas"), y gozaban de un distintivo de autenticidad premunido por el respectivo sello (el "ius sigilii" de la época medieval), carecían de la fuerza atribuida a los instrumentos públicos principalmente a causa de la forma como se confeccionaban. Moreno Navarrete explica que estas documentaciones (que fueron denominadas "documentos auténticos" por la doctrina posterior a las Partidas), solamente hacían plena prueba en contra de la persona que las mandaba sellar, pero no en su favor, por tratarse de escrituras que contenían hechos privativos suyos y no ajenos ${ }^{87}$.

Pues bien, lo que vemos aquí es un antecedente de la precisión conceptual que estamos proponiendo, conforme a la cual los documentos dotados de fe pública necesariamente deben tener un valor probatorio más elevado que los documentos carentes de este atributo. Y ello no obstante tratarse, en los dos casos, de documentos públicos, tal como lo reconocían las Partidas al incluirlos en la misma categoría de las "cartas publicas" (Partida 3a, Título 18, Ley 105).

Cabe señalar que esta tradición mantiene vigencia en la legislación moderna espańola, tal como puede constatarse en los dos numerales del art. 319 LEC No 1/2000, en los que se establecen regímenes diferenciados para determinar la fuerza probatoria de los documentos públicos.

En el primer párrafo de esta norma, se indica que los documentos públicos comprendidos en los números $1^{\circ}$ a $6^{\circ}$ del art. 317 (que corresponde a documentos dotados de fe pública), "harán plena prueba del hecho, acto o estado de cosas que documenten, de la fecha en que se produce esa documentación y de la identidad de los fedatarios y demás personas que, en su caso, intervengan en ella". La expresión "plena prueba" es típica de un modelo de tarifa legal, como el que describimos más arriba al aludir a los arts. 1700 y 1706 CC.

En el segundo párrafo del art. 319 se establece una disposición especial para los documentos administrativos carentes de fe pública. Según esta norma, "la fuerza probatoria de los documentos administrativos no com-

85 Las Siete Partidas (1829), p. 324.

86 Bono, José (1982) Historia del Derecho Notarial español. Edad Media. Literatura e instituciones. Madrid: Junta de Decanos de los Colegios Notariales de España. T. I.2, 392 pp., p. 209.

87 Moreno Navarrete, Miguel Ángel (200I) La prueba documental. Estudio histórico-jurídico y dogmático. Madrid: Marcial Pons, 437 pp., pp. 265-266. 
prendidos en los números 5 y 6 del artículo 317 a los que las leyes otorguen el carácter de públicos, será la que establezcan las leyes que les reconozcan tal carácter. En defecto de disposición expresa en tales leyes, los hechos, actos o estados de cosas que consten en los referidos documentos se tendrán por ciertos, a los efectos de la sentencia que se dicte, salvo que otros medios de prueba desvirtúen la certeza de lo documentado". Cuando la ley española indica que "se tendrán por ciertos", en lugar de usar la fórmula "harán plena prueba", está marcando una diferencia en cuanto al grado de valor probatorio, que es menor para los documentos públicos que son fruto del ejercicio de funciones públicas. Sobre la base de estas disposiciones, Montero Aroca se refiere a los documentos que emanan de órganos públicos y que carecen de fe pública, como "documentos públicos administrativos de segunda clase", dada la menor fuerza probatoria que les asigna la ley ${ }^{88}$.

\section{(4.2.) DIFERENCIACIÓN DEL VALOR PROBATORIO}

A propósito de lo último, hacemos presente que si bien en el Derecho Público los aspectos orgánicos y formales son fundamentales, como también lo es la seguridad de las situaciones y relaciones jurídicas, no por ello cabe equiparar las nociones que comentamos (fe pública y función pública).

El valor probatorio debe ser distinto. De aceptar la tesis de PARejo tendríamos que incluir en un mismo bloque a documentos como, por ejemplo, los oficios que remite un órgano a otro, las presentaciones con un visto bueno y media firma de funcionarios públicos, los documentos electrónicos emitidos por un servicio público bajo firma electrónica avanzada, las partidas y certificados de nacimiento, matrimonio y defunción, las cédulas de identidad, los pasaportes y las escrituras públicas. A los fines de la prueba judicial civil, estos documentos no pueden valer lo mismo, ya que en unos (oficios, visto bueno) falta la fe pública que concurre en otros (documentos electrónicos con firma electrónica avanzada, partidas y certificados, cédulas de identidad, pasaportes, escrituras públicas). De hecho, esta diferenciación ha estado presente en la doctrina penal chilena, tal como se aprecia en las explicaciones de Ruiz Pulido en las que se plantea una distinción similar considerando el tema de la eficacia 
jurídica de estos documentos y la aptitud que tienen para demostrar su autenticidad $^{89}$.

Todavía más: llevando la referida tesis al extremo, nos veríamos en la obligación de aceptar que no median mayores diferencias entre la prueba producida a través de los instrumentos públicos del art. 1699 CC y la que tiene lugar por medio de los documentos oficiales expedidos por funcionarios de servicios públicos, aun cuando ellos no posean la condición de ministros de fe. Es lo que piensan Santa Cruz y Moreno Vaccaro, para quienes estas modalidades documentales deberían someterse a las normas de prueba tasada de los arts. 1700 y 1706 CC. Tal conclusión ha sido rechazada por la Corte Suprema en fallos de 4 de mayo de 1953 y de 30 de marzo de $2010^{90}$, para así sostener -respectivamente- que los documentos extendidos por funcionarios de la Empresa de los Ferrocarriles del Estado y por la Autoridad Marítima chilena, no pueden ser valorados de acuerdo con tales preceptos.

Cabe hacer presente que la mencionada equivalencia ha sido utilizada por la jurisprudencia italiana, al extender la aplicación de las reglas tarifadas previstas en el art. 2700 CC para los "actos públicos" que contienen contratos y negocios privados (equivalentes a nuestros "instrumentos públicos") a los documentos elaborados por órganos y funcionarios de la Administración. Las fuertes críticas dirigidas por la doctrina procesal de ese país dicen relación precisamente con el punto que analizamos, puesto que el problema se produce como consecuencia de la falta de distinción entre los dos planos (fe pública y función pública) ${ }^{91}$.

Como ya señalamos, en nuestra opinión los únicos casos en los que resulta justificable la aplicación del sistema de valoración tasada son aquellos en los que interviene la fe pública, en atención a las mayores seguridades que entrega esta institución en el proceso de formación documental. Si no hacemos la separación de nociones, todos los documentos públicos podrían, eventualmente, quedar sujetos a este régimen de eficacia, tal como lo propusieron Santa Cruz y Moreno Vaccaro. Ello, a no dudarlo, tergiversa todo el sistema de esta evidencia.

Esto ha sido subrayado en España por autores como OrmazÁbal Sánchez y García Ureta, que coinciden en cuanto a la necesidad de

89 Ruiz Pulido, Guillermo (2002) "Instrumento público y ley penal". Revista de Derecho. Santiago: Consejo de Defensa del Estado. No 6, pp. 59-90, pp. 73-82.

90 Corte Suprema. 4 de mayo de 1953. "Sociedad Iroumé Bouzout y Compañía con Empresa de los Ferrocarriles del Estado". Revista de Derecho y Jurisprudencia. T. 50, sec. 1a, pp. 127-131, c. $2^{\circ}$, p. 129; CS. Rol No 7951-09, c. 13º.

91 Comoglio, Luigi Paolo (2010) Le prove civili. $3^{\text {a }}$ edición. Turín: Utet Giuridica, 935 pp, pp. 58-59, pp. 429-447. 
marcar una división entre los documentos públicos regulados por el Código Civil de ese país, que están sometidos a un sistema tarifado, y los documentos públicos administrativos, respecto de los cuales existen otros preceptos sobre eficacia probatoria, con una norma general y supletoria contenida en el ya citado art. 319 No 2 LEC No 1/2000. Ambos autores parten de la base que el mero ejercicio de una función pública no entraña necesariamente la capacidad para dar fe pública, razón por la cual es indispensable identificar con precisión el estatuto probatorio de estos dos tipos de documentos públicos ${ }^{92}$.

\section{(4.3.) NECESIDAD DE EVITAR PRIVILEGIOS PROBATORIOS}

La distinción que proponemos se aviene con la garantía del debido proceso legal y con la igualdad procesal, al evitar que los órganos y servicios públicos cuenten con un privilegio en la prueba documental pública. Una adscripción a la doctrina de PAREjo y a la aplicación analógica de los arts. 1700 y 1706 CC, serviría de fundamento para que todos los documentos generados al interior de organismos estatales adquieran ab initio plena fuerza probatoria, lo que traería como resultado que los servicios públicos estarían legitimados para preconstituir evidencias en su favor. Ello daría lugar a un nuevo privilegio procesal del Estado y de los órganos de la Administración Pública, con un innegable menoscabo de las referidas garantías judiciales ${ }^{93}$.

Sobre el particular, son pertinentes las prevenciones que formuló Bentham en cuanto al valor de las pruebas confeccionadas por una de las partes, a las que denominó "pruebas semipreconstituidas". Para este autor, las evidencias que admiten el calificativo de "pruebas preconstituidas" son las elaboradas por las dos partes interesadas. Cuando Bentham se refiere a los escritos auténticos que han sido hechos con arreglo a ciertas formas legales para ser empleados eventualmente con carácter de prueba jurídica y los define como "pruebas preconstituidas", lo está haciendo pensando específicamente en documentos otorgados por todas las partes interesa-

Ormazábal SÁnchez, Guillermo (2000) La prueba documental y los medios e instrumentos idóneos para reproducir imágenes o sonidos o archivar y conocer datos. Madrid: La Ley, 237 pp., pp. 69-70; García Ureta, Agustín (2006) La potestad inspectora de las Administraciones Públicas. Barcelona/Madrid: Marcial Pons, 355 pp., pp. 182-193.

93 Una crítica a estos privilegios, en Romero Seguel, Alejandro (2011) "Algunos privilegios procesales de la administración del Estado en la litigación civil (Dos mecanismos para su atenuación o supresión)". En: Arancibia Mattar, J; Martínez Estay, J. I.; Romero Seguel, A. (coordinadores). Litigación pública. Santiago: AbeledoPerrot / Thomson Reuters, pp. 437-465. 
das ${ }^{94}$. En cambio, si los escritos han sido redactados por una de las partes, entonces debe emplearse un concepto diverso: el de "prueba semipreconstituida", que no es confeccionada a partibus sino ex parte, es decir, por una sola de las partes ${ }^{95}$.

El cuidado al que se refiere este autor atańe a la fuerza de estas pruebas, ya que no puede dar lo mismo que una evidencia provenga exclusivamente de uno de los sujetos involucrados en el conflicto; mucho menos cuando ese sujeto ostenta una potestad de mando sobre el otro. Usando los términos de esta teoría, podríamos decir que las documentaciones confeccionadas por órganos y funcionarios públicos, tienen -en principio- el carácter de pruebas semipreconstituidas (sin fe pública), y como tales poseen un valor menor frente a las pruebas preconstituidas (con fe pública).

\section{(4.4.) SEguridad JURÍdica Y PRINCIPIO DE PROTECCIÓN DE LA CONFIANZA LEGÍTIMA}

Hay que tener presente que para salvaguardar la seguridad jurídica en el Derecho Público no es necesario acudir al concepto de fe pública. El principio de protección de la confianza legítima contiene elementos suficientes para resguardar la posición de los administrados en relación con la titularidad y estabilidad de sus derechos y expectativas.

Según este principio, los ciudadanos tienen el derecho a recibir amparo judicial frente a las modificaciones de relaciones o situaciones jurídicas efectuadas por la Administración Pública, cuando esta ha venido actuando de una determinada manera, generándose así una legítima y razonable expectativa de que continuará haciéndolo en iguales términos en situaciones similares ${ }^{96}$.

Por lo mismo, en lugar de referirnos a la fe pública para lograr la seguridad a la que alude Parejo, es mejor acudir al mencionado principio que permite dar amparo a las situaciones generadas por actuaciones

94 Bentham, Jeremías (1971) Tratado de las pruebas judiciales. Obra compilada de los manuscritos del autor por E. Dumont. Traducción de Manuel Ossorio Florit. Buenos Aires: Ejea. Vol. I, 404 pp., p. 32.

95 Bentham (1971) 32.

96 Sobre este principio, destacamos: Castillo Blanco, Federico (1998) La protección de la confianza en el Derecho Administrativo. Madrid: Marcial Pons, 381 pp., pp. 108-115; Díez SaStre, Silvia (2008) El precedente administrativo. Fundamentos y eficacia vinculante, Madrid: Marcial Pons, 476 pp., pp. 375-379; Bermúdez Soto, Jorge (2014) Derecho Administrativo general. $3^{\text {a }}$ edición. Santiago: LegalPublishing / Thomson Reuters, 794 pp., pp. 110125; Cordero Vega, Luis (2015) Lecciones de Derecho Administrativo. 2a edición. Santiago: Thomson Reuters, 786 pp., pp. 307-312 
públicas que externamente se presentan como legítimas. Por otra parte, la eficacia de las potestades de los órganos estatales está cubierta por la presunción de legalidad (art. 30 inc. $8^{\circ}$ Ley No 19.880 de 2003), de modo que tampoco tiene sentido construir una noción amplia de fe pública para explicar la imperatividad y ejecutabilidad de los actos administrativos.

\section{5) ASPECTOS QUE PERMITEN HACER LA DISTINCIÓN ENTRE FE PÚBLICA Y FUNCIÓN PÚBLICA EN LA PRUEBA DOCUMENTAL PÚBLICA}

\section{(5.1.) CaraCterísticas Del PROCEDIMIENTO DE CONFECCIÓN DOCUMENTAL}

A diferencia de lo que ocurre con la función pública, la institución de la fe pública presenta dos componentes que aseguran con más intensidad la autenticidad documental y, al mismo tiempo, justifican el mayor valor legal de los documentos investidos de este atributo. Se trata, primero, de la presencia de una regulación especialmente diseñada para la confección de documentos públicos y, segundo, de una más nítida separación entre el autor del documento y el autor de la declaración.

En cuanto a lo primero, recordemos que la institución de la fe pública considera la presencia de un procedimiento típico cuyo objeto es regular los actos de documentación. Según dijimos, para graficarlo en el ámbito notarial se habla de un "proceso notarial" 97 , un "procedimiento notarial" 98 o un "rito instrumental" 99 . De esta manera se alude a la sucesión de actuaciones que deben desarrollarse al interior del notariado para la confección de documentos, en todas las cuales interviene la fe pública como elemento identificador de la actividad documentadora.

Esta regulación especial permite dotar de mayores seguridades al documento público acompañado de fe pública, lo que no ocurre con los documentos oficiales, que quedan simplemente incluidos dentro del conjunto de actividades de los organismos y funcionarios públicos.

Etchegaray (2010) 35.

Cruz Barrios (i 973) 110-113; Vidal Domínguez (1997) 145.

GonzÁlez (1953) 123; Pelosi (2006) 179-181. 


\section{(5.2.) DISTINCIÓN ENTRE EL AUTOR DEL DOCUMENTO Y EL AUTOR DE LA DECLARACIÓN CONTENIDA EN EL DOCUMENTO}

El referido procedimiento también sirve para trazar una línea divisoria más nítida entre el autor del documento (asunto vinculado a la autenticidad) y el autor de la declaración contenida en el documento (cuestión referida a la veracidad del contenido). Esto, a su vez, sirve de base para atribuir mayor fuerza probatoria legal a la veracidad de los documentos públicos dotados de fe pública, atendida la separación que media entre una esfera y otra. En otras palabras, el autor del documento no se involucra con el contenido de las declaraciones de voluntad o de conocimiento. De ahí la regla tarifada del art. 1700 inc. $1^{\circ} \mathrm{CC}$, donde se establece un valor de "plena fe" en cuanto a la verdad de las declaraciones de las partes otorgantes; no se mencionan las declaraciones del ministro de fe, pues él no presta su voluntad en el acto o contrato documentado.

Lo que sucede es que en el Derecho chileno vigente la actividad de los ministros de fe es eminentemente certificadora o autenticadora, sin mayor intervención en el acto jurídico o en las declaraciones consignadas en el respectivo documento público, como tampoco en los efectos derivados de aquellos. Incluso más, para autores como NúŃEZ LaGos, que defienden la presencia del notario como asesor de las partes otorgantes, la intervención del fedatario en la creación documental es pasiva o "recepticia"; es una participación de "visu et auditu suis sensibus". El notario no concurre con su voluntad a la formación del acto jurídico, como sí lo hacen los comparecientes; lo que hace es certificar la autenticidad de los documentos y, cuando más, asistir a las partes. Por ello, el notario que autoriza una escritura actúa de un modo distinto al juez que dicta una sentencia, ya que el primero no manda ni decide como sí lo hace el segundo $^{100}$.

Este parangón lo podemos aplicar a los documentos generados con motivo del ejercicio de funciones públicas, en los que los funcionarios públicos sí consignan declaraciones de voluntad relativas a la gestión pública que ejecutan en razón de su cargo, ejerciendo potestad de mando o de decisión. Los mismos dos aspectos que caracterizan a la fe pública tienen una configuración diversa en el ámbito de las documentaciones creadas durante el ejercicio de funciones públicas. Primero, porque en estos documentos no encontramos procedimientos típicos y especiales en materia de

100 NúŃEZ Lagos, Rafael (1986 e) "Los esquemas conceptuales del instrumento público". Estudios de Derecho Notarial. Madrid: Instituto de Espańa. T. II, pp. 3-88, pp. 78 y 79. 
documentación; segundo, porque generalmente se produce una confusión entre el autor del documento y el autor de la declaración.

\section{(5.3.) AUSENCIA DE PROCEDIMIENTO EXPRESO Y CONFUSIÓN DE AUTORÍAS EN LOS DOCUMENTOS CONFECCIONADOS DURANTE EL EJERCICIO DE FUNCIONES PÚBLICAS}

Estos documentos no son propiamente el resultado de procedimientos destinados a regular la confección documental. Lo regulado es el desarrollo de funciones públicas, siendo los documentos la faceta formal o externa de esa reglamentación. Podríamos afirmar que en esta área la actividad documentadora es secundaria o accesoria a otra actividad, consistente en la gestión pública.

$\mathrm{Al}$ respecto, son interesantes las precisiones formuladas en la ya citada sentencia de 6 de agosto de 1963 de la Corte de Apelaciones de Santiago, en la que se analizó la naturaleza jurídica de un certificado de notas extendido bajo sello y firma de la Directora de un establecimiento de educación pública. Por una parte, se sostuvo que no procedía calificarlo como un documento público a efectos penales, pues dada la ausencia de regulación legal acerca de la forma, solemnidades y competencia con que debían ser extendidos, resultaba inadmisible estimar que su falsificación ofendía la fe pública. Por otra parte, se indicó que en atención al contexto en que fue elaborado el citado certificado, debía ser considerado un documento oficial que, como tal, envuelve una presunción de autenticidad.

La sentencia expresa que a raíz de la falta de regulación en los precitados rubros, desde un punto de vista formal no procedía calificar a estas clases documentales como documentos públicos ("instrumentos públicos", dice el fallo), "porque no están regidos, en cuanto a la competencia $y$ al formalismo, por normas de carácter legal. En otras palabras, la fe que puede atribuirseles no está sancionada por la ley". Agrega que "si bien desde el punto de vista sustancial ellos tienen una finalidad probatoria respecto de hechos con significación jurídica, como es el cumplimiento de requisitos para la promoción de curso o la opción a ciertos empleos, esta circunstancia no es suficiente, en nuestra legislación, para otorgarles el carácter de públicos. Con su falsificación no se ofende la fe pública garantizada por la ley"101.

Junto con lo anterior, hay que tener presente que los aludidos documentos no cuentan con la intervención de un sujeto o elemento externo 
que los autentifique. Según decíamos, los ministros de fe intervienen para certificar la autenticidad de los documentos públicos, sin tener mayor injerencia en el contenido de los actos jurídicos o declaraciones registrados en ellos. La actividad notarial, como afirmaba NúŃEZ LAGos, consiste en ver, oír y narrar ("visu et auditu suis sensibus"); no están llamados a mandar ni decidir ${ }^{102}$. La actividad pública, en cambio, está dirigida a mandar.

Por tanto, es posible que el contenido de estos documentos corresponda únicamente a una manifestación de voluntad del mismo funcionario que los expide. Lo que equivale a señalar que en estos supuestos los documentos no cuentan con una certificación dada por un sujeto ajeno al contenido, sino muy por el contrario el autor del documento y el autor de la declaración se reúnen en una misma persona. Pensemos en los múltiples ejemplos de documentos oficiales, como los oficios remitidos por jefes de servicios públicos, los informes elaborados por funcionarios de organismos fiscalizadores y las actas de inspección levantadas por funcionarios públicos.

Esta situación ha sido expuesta por PAILlás a propósito del significado de los instrumentos públicos regulados por los arts. 1699, $1700 \mathrm{y}$ $1706 \mathrm{CC}$, en los que el oficial público (ministro de fe) interviene con el preciso propósito de otorgar fe pública (autorizar) a un documento donde se contienen declaraciones de voluntad de otros sujetos (las partes otorgantes). En distinta posición se encuentran los documentos oficiales que emanan de autoridades públicas, en los cuales no existen solemnidades ni se da fe de actos otorgados por particulares, sino que se trata de documentaciones que emanan de autoridades o funcionarios públicos que mandan, resuelven o realizan otra actividad propia de su cargo ${ }^{103}$.

La distinción entre fe pública y función pública sirve de base para cuestionar la fuerza probatoria de documentos extendidos por funcionarios a los que la ley califica como "ministros de fe", pero que desarrollan actividades que no reúnen los dos elementos institucionales que explicamos antes. Esto es particularmente relevante en el caso de las "actas de fiscalización o de inspección" elaboradas por funcionarios que no cumplen con las aludidas exigencias fundamentales.

El análisis de los puntos antes mencionados exige múltiples profundizaciones que no corresponde desarrollar en este lugar, sobre todo lo atinente a los niveles o grados de valor probatorio de los documentos. Por ahora, nos limitamos a dejar anotada la necesidad de distinguir los dos

102 NúŃEz Lagos (1986 e) 78.

103 Paillás Peña, Enrique (2002) Estudios de Derecho probatorio. 2a edición. Santiago: Editorial Jurídica de Chile, 159 pp., pp. 43 y 44. 
conceptos para una adecuada comprensión de la prueba por documentos públicos.

\section{CONCLUSIONES}

Sobre la base de lo expuesto, podemos formular las siguientes conclusiones:

a) Desde una perspectiva probatoria cabe distinguir dos clases de documentos públicos: unos provistos de fe pública y otros que son el resultado del ejercicio de funciones públicas.

b) La fe pública es un elemento de la prueba por medio de documentos públicos, que puede ser definido como una institución jurídica compuesta por un conjunto de disposiciones legales cuyo objeto central es garantizar la autenticidad documental.

c) Al afirmar que es una institución jurídica estamos enfatizando el carácter normativo y objetivo de la fe pública, separándola de los ministros de fe. Por tal razón, en el plano de las pruebas cabe aceptar la presencia de documentos públicos investidos de este atributo aun cuando en su confección no hayan intervenido fedatarios. Un ejemplo es el documento electrónico suscrito mediante firma electrónica avanzada.

d) El núcleo conceptual de la fe pública está integrado por las normas jurídicas que regulan los procedimientos de confección documental y que garantizan la autenticidad de los documentos públicos. Así, los documentos públicos revestidos de fe pública siempre tienen la aptitud para establecer por sí mismos su autenticidad, esto es, su legitimidad como continentes de información probatoria.

e) El fundamento de la fe pública es la seguridad del tráfico jurídico, que en el ámbito probatorio se proyecta a través de normas de valoración legal. En consecuencia, existe una íntima relación entre documentos públicos dotados de fe pública, seguridad del tráfico jurídico y valoración legal de la prueba. Esto implica que la autenticidad de estos documentos se somete a normas de prueba legal. Incluso más, las mismas garantías que otorgan las normas reguladoras de la confección de documentos públicos justifican que el legislador adopte en estos casos un régimen de valoración más intenso, que podemos llamar tarifa legal, que comprende su autenticidad e incluso puede abarcar la veracidad de su contenido. Este es el fundamento de los arts. 1700 y 1706 CC. De esta manera, los documentos públicos son pruebas que no están sometidos al sistema de valoración según las reglas de la sana crítica. 
f) En la prueba por medio de documentos públicos no puede confundirse la fe pública con la función pública, en especial en cuanto al valor de la evidencia. Si bien en ambos casos concurren elementos que permiten reconocer normativamente la autenticidad documental, tratándose de los documentos emanados del ejercicio de funciones públicas (por lo general, denominados "documentos oficiales"), el valor probatorio es menor. Esto último se debe, primero, a la ausencia de procedimientos expresos reguladores de la actividad documentadora, lo que disminuye las garantías de autenticidad, y segundo, a la confusión entre autor del documento y autor de la declaración documentada, lo que exige restringir la fuerza probatoria en cuanto al contenido de esta evidencia para así evitar situaciones de privilegio en favor de órganos públicos.

\section{BIBLIOGRAFÍA}

Bentham, Jeremías (1971) Tratado de las pruebas judiciales. Obra compilada de los manuscritos del autor por E. Dumont. Traducción de Manuel Ossorio Florit. Buenos Aires: Ejea. Vol. I, 404 pp.

Bermúdez Soto, Jorge (2014) Derecho Administrativo general. $3^{a}$ edición. Santiago: LegalPublishing / Thomson Reuters, 794 pp.

Bonnier, Eduardo (1929) Tratado teórico y práctico de las pruebas en Derecho Civil y en Derecho Penal. Traducción de Jose de Vicente y Caravantes. 5a edición, Madrid: Reus. T. II, 676 pp.

Bonet Navarro, José (2009) La prueba en el proceso civil. Cuestiones fundamentales. Madrid: Difusión Jurídica, $361 \mathrm{pp}$.

Bono, José (1982) Historia del Derecho Notarial español. Edad Media. Literatura e instituciones. Madrid: Junta de Decanos de los Colegios Notariales de España. T. I.2, 392 pp.

Bravo Lira, Bernardino (2009) "Oficio y oficina, dos etapas en la historia del Estado indiano". En El juez entre el Derecho y la ley, en el mundo hispánico. Del Estado de Derecho al Derecho del Estado (siglos $X V I$ a XXI). 2a edición. Santiago: LegalPublishing, pp. 129-163.

Calvo Castro, Gonzalo (1981) "Sistemas de apreciación de la prueba". En Sergio Dunlop Rudolffi (coordinador). Nuevas orientaciones de la prueba. Santiago: Editorial Jurídica de Chile, pp. 133-155.

Carrara, Francesco (1964) Programa de Derecho Criminal. Traducción de José Ortega y Jorge Guerrero. Bogotá: Temis. Vol. VII, 527 pp.

Castillo Blanco, Federico (1998) La protección de la confianza en el Derecho Administrativo. Madrid: Marcial Pons, $381 \mathrm{pp}$.

Cordero Vega, Luis (2015) Lecciones de Derecho Administrativo. 2a edición. Santiago: Thomson Reuters, 786 pp. 
Cousiño Mac-Iver, Luis (1944) La falsificación de instrumento privado (Ensayo de construcción juridica del delito en Chile). Santiago: Imprenta Stanley, $60 \mathrm{pp}$.

Couture, Eduardo J. (1989) "El concepto de fe pública (Introducción al estudio del Derecho notarial)". En Estudios de Derecho Procesal Civil. $3^{\text {a }}$ edición, Buenos Aires: Depalma. T. II, pp. 13-125.

Couture, Eduardo J. (1993) Fundamentos del Derecho Procesal Civil. $3^{\mathrm{a}}$ edición. Buenos Aires: Depalma, 524 pp.

Comoglio, Luigi Paolo (2010) Le prove civili. $3^{a}$ edición. Turín: Utet Giuridica, 935 pp.

Claro Solar, Luis (1992) Explicaciones de Derecho Civil chileno y comparado. Las obligaciones. Santiago: Editorial Jurídica de Chile. Vol. VI, t. XII, 822 pp.

Cruz Barrios, Norman (1973) Derecho notarial chileno. La función notarial y el instrumento público, en especial la escritura pública. Teoría, doctrina, legislación y jurisprudencia. Santiago: López-Vianco, $327 \mathrm{pp}$.

Cruz Rivero, Diego (2006) Eficacia formal y probatoria de la firma electrónica. Madrid: Marcial Pons, 356 pp.

Díez Sastre, Silvia (2008) El precedente administrativo. Fundamentos y eficacia vinculante. Madrid: Marcial Pons, $476 \mathrm{pp}$.

Díaz Sanguesa, Alfonso (1957) La fe pública y el Derecho notarial. Santiago: Editorial Universitaria, 154 pp.

Etcheberry, Alfredo (1961) "El objeto jurídico de los delitos de falsedad documental". Revista de Ciencias Penales. Santiago: Instituto de Ciencias Penales-Chile. T. XX, No 1, pp. 33-66.

Etcheberry, Alfredo (1998) Derecho Penal. 3a Edición. Santiago: Editorial Jurídica de Chile. T. IV, 382 pp.

Etchegaray, Natalio Pedro (2010) Escrituras y actas notariales. 5a edición. Buenos Aires: Astrea, 359 pp.

Fernández de Buján, Antonio (2001) "Fides publica e instrumenta publice confecta en Derecho romano". Revista de Estudios Latinos. Universidad Complutense de Madrid. No 1, pp. 189-200.

Ferrajoli, Luigi (2011) Principia iuris. Teoría del Derecho y de la democracia. 1. Teoría del Derecho. Traducción de Perfecto Andrés Ibánez et al. Madrid: Trotta, 952 pp.

Filangieri, Cayetano (1823) Ciencia de la legislación. Traducción de Juan Ribera. 2a edición. Burdeos: Imprenta P. Beaume. T. III, 364 pp.

Fueyo Laneri, Fernando (1982) Teoría general de los registros. Buenos Aires: Astrea, 248 pp.

Fueyo Laneri, Fernando (1990) Instituciones de Derecho Civil moderno. Santiago: Editorial Jurídica de Chile, 602 pp. 
Gaete González, Eugenio (2009) Instrumento público electrónico. 3a edición. Barcelona: Bosch, 551 pp.

Gallegos Sanhueza, Walter (2000) Crimenes y simples delitos contra la fe pública. Santiago: Editorial Jurídica Aremi, 288 pp.

García Ureta, Agustín (2006) La potestad inspectora de las Administraciones Públicas. Barcelona/Madrid: Marcial Pons, 355 pp.

Garrido Montt, Mario (2008) Derecho Penal. Parte especial. 4a edición. Santiago: Editorial Jurídica de Chile. T. IV, 259 pp.

González, Carlos Emérito (1953) Teoría general del instrumento público (Introducción al Derecho notarial argentino y comparado). Buenos Aires: Ediar. 475 pp.

GuZmán DÁlbora, José Luis (2009) "Falsedad documental y supresión de actuaciones en expedientes judiciales". En Estudios y defensas penales. $3^{\mathrm{a}}$ edición. Santiago: LegalPublishing, pp. 511-523.

Lazo, Santiago (1936) Los códigos chilenos anotados. Del Notariado. Legislación y jurisprudencia. Santiago: Imprenta y Litografía La Ilustración, $139 \mathrm{pp}$.

Liebman, Enrico Tullio (1980) Manual de Derecho Procesal Civil. Traducción de Santiago Sentís Melendo. Buenos Aires: Ejea, 725 pp.

Lira, José Bernardo (1880) Prontuario de los juicios. $3^{\text {a }}$ edición. Santiago: Imprenta de "el correo". T. I, $432 \mathrm{pp.}$

Manzini, Vincenzo (1950) Trattato di Diritto Penale italiano. Delitti contro il sentimento religioso e la pietà dei defunti. Delitti contro l'ordine pubblico. Delitti contro la pubblica incolumità. Delitti contro la fede pubblica. Turín: Utet. Vol. 6, 936 pp.

MaYer Lux, Laura (2014) "La falsificación de instrumentos privados: ¿una estafa especial?”. Revista de Derecho. Universidad Austral de Chile. Vol. 27, $\mathrm{N}^{\circ}$ 2, pp. 217-241.

Mayer Lux, Laura; Vera Vega, Jaime (2015) "Historia del objeto material del delito de falsedad documental punible". Revista de Estudios Histórico-Jurídicos. Pontificia Universidad Católica de Valparaíso. No 37, pp. 325-346.

Mayer Lux, Laura; Vera Vega, Jaime (2016) "El concepto de documento público y de documento oficial para efectos de los delitos de falsedad documental: consideraciones histórico-dogmáticas para su determinación”. En Claudia Cárdenas Aravena; Jorge Ferdman Niedmann. (coordinadores). El Derecho Penal como teoría y como práctica. Libro en homenaje a Alfredo Etcheberry Orthusteguy. Santiago: Thomson Reuters, pp. 751-776.

Montero Aroca, Juan (2012) La prueba en el proceso civil. $7^{\text {a }}$ edición. Navarra: Civitas / Thomson Reuters / Aranzadi, 625 pp.

Moreno Navarrete, Miguel Ángel (2001) La prueba documental. Estudio histórico-jurídico y dogmático. Madrid: Marcial Pons, 437 pp. 
Moreno Vaccaro, Rubén (1957) Los documentos oficiales. Santiago: Editorial Universitaria, $133 \mathrm{pp}$.

Núñez Lagos, Rafael (1950) Hechos y derechos en el documento público. Madrid: Publicaciones del Instituto Nacional de Estudios Jurídico, $414 \mathrm{pp}$.

NúNÉz Lagos, Rafael (1986 a) "La fe pública". En Estudios de Derecho Notarial. Madrid: Instituto de España. T. I, pp. 329-362.

NúŃEz Lagos, Rafael (1986 b) "Fe pública especial". En Estudios de Derecho Notarial. Madrid: Instituto de España. T. I, pp. 403-451.

NúŃEz Lagos, Rafael (1986 c) "Perfiles de la fe pública". En Estudios de Derecho Notarial. Madrid: Instituto de España. T. I, pp. 455-480.

NúNEz Lagos, Rafael (1986 d) "El Derecho Notarial". En Estudios de Derecho Notarial. Madrid: Instituto de España. T. I, pp. 1-47.

NúŃez Lagos, Rafael (1986 e) "Los esquemas conceptuales del instrumento público". En Estudios de Derecho Notarial. Madrid: Instituto de España. T. II, pp. 3-88.

OrmazÁbal SÁnchez, Guillermo (2000) La prueba documental y los medios e instrumentos idóneos para reproducir imágenes o sonidos o archivar y conocer datos. Madrid: La Ley, $237 \mathrm{pp}$.

Paillás Peña, Enrique (2002) Estudios de Derecho probatorio. 2a edición. Santiago: Editorial Jurídica de Chile, 159 pp.

Parejo Alfonso, Luciano (1994) "Fe pública y administración pública". En Junta de Decanos de los Colegios Notariales de España. Ministerio de Justicia. La fe pública. Madrid: Colegios Notariales de España, pp. 155-189.

Pelosi, Carlos A. (2006) El documento notarial. $4^{a}$ reimpresión. Buenos Aires: Astrea, 349 pp.

Politoff Lifschitz, Sergio; Matus Acuña, Jean Pierre; Ramírez González, María (2009) Lecciones de Derecho Penal chileno. Parte especial. 2a edición. Santiago: Editorial Jurídica de Chile, 689 pp.

Quintano Ripollés, Antonio (1952) La falsedad documental. Madrid: Reus, 270 pp.

Rioseco Enríquez, Emilio (2002) La prueba ante la jurisprudencia. Derecho Civil y Procesal Civil. $4^{a}$ edición. Santiago: Editorial Jurídica de Chile. T. I, 493 pp.

Rivacoba y Rivacoba, Manuel de (1986) “Objeto jurídico y sujeto pasivo de la falsificación de moneda”. Revista Doctrina Penal. Año 9 $\mathrm{N}^{\circ}$ s 33-34, pp. 41-53.

Rodríguez Adrados, Antonio (1996) "Fe pública". En Escritos Jurídicos. Madrid: Colegios Notariales de España. Vol. III, pp. 175-186.

Rodríguez Collao, Luis; Vera Vega, Jaime (2004) "El bien jurídico protegido en los delitos de falsedad". Revista Escuela de Derecho. Universidad Católica de Temuco. No 5, pp. 109-135. 
Rojas Aguirre, Luis Emilio (2012) "Historia dogmática de la falsedad documental". Revista de Derecho. Pontificia Universidad Católica de Valparaíso. $\mathrm{N}^{\circ} 39, \mathrm{~N}^{\circ} 2$, pp. 545-583.

Rojas Aguirre, Luis Emilio (2014 a) "Falsedad documental como delito de engaño". Revista Chilena de Derecho. Pontificia Universidad Católica de Chile. Vol. 41, No 2, pp. 523-554.

Rojas Aguirre, Luis Emilio (2014 b) "Deconstrucción del método dominante de comprensión de los delitos de falsedad documental". Politica Criminal. Vol. 9, No 18, A.6, pp. 477-520. Disponible en http://www.politicacriminal.cl/Vol_09/n_18/Vol19N18A6.pdf [fecha de visita: 16 de enero de 2016].

Rojas Aguirre, Luis Emilio (2015) "Falsedad documental como delito contra el derecho a la verdad". Revista de Estudios de la Justicia. Universidad de Chile. No 22, pp. 143-179.

Rojas Aguirre, Luis Emilio (2016) "Iter criminis sin solución de continuidad en los delitos de falsedad documental y uso malicioso de documento falso". En Claudia Cárdenas Aravena; Jorge Ferdman Niedmann (coordinadores). El Derecho Penal como teoría y como práctica. Libro en homenaje a Alfredo Etcheberry Orthusteguy. Santiago: Thomson Reuters, pp. 777-796.

Romero Seguel, Alejandro; Martínez Estay, José Ignacio (2005) "Sobre la pretendida obligación de firmar ante los notarios los instrumentos públicos y privados". Revista de la Asociación de Notarios y Conservadores de Chile. Santiago, pp. 13-22.

Romero Seguel, Alejandro (2011) "Algunos privilegios procesales de la administración del Estado en la litigación civil (Dos mecanismos para su atenuación o supresión)”. En Jaime Arancibia Mattar; José Ignacio Martínez Estay; Alejandro Romero Seguel (coordinadores). Litigación pública. Santiago: AbeledoPerrot / Thomson Reuters, pp. 437-465.

Ruiz Pulido, Guillermo (2002) "Instrumento público y ley penal". En Revista de Derecho. Santiago: Consejo de Defensa del Estado. No 6. pp. 59-90.

Sandoval López, Ricardo (2003) Derecho del comercio electrónico. Santiago: Editorial Jurídica de Chile, 314 pp.

Sandoval López, Ricardo (2004) Seguridad en el comercio electrónico. Firma electrónica: análisis de la ley $N^{\circ}$ 19.799. Santiago: LexisNexis, 305 pp.

Santa Cruz Serrano, Víctor (1941) "El instrumento público". Revista de Derecho y Jurisprudencia. T. 38, pp. 142-164;

Santa Cruz Serrano, Víctor (1942) "El instrumento público". Revista de Derecho y Jurisprudencia. T. 39, pp. 5-60 
Serra Domínguez, Manuel (2009) "Prueba documental". En Estudios de Derecho Procesal. Lima: Communitas, pp. 201-248.

Villacampa Estiarte, Carolina (1999) La falsedad documental: análisis jurídico-penal, Barcelona: Cedecs, 906 pp.

Vargas Pinto, Tatiana (2013) Falsificación de instrumento privado. Un estudio práctico entre la falsificación y la estafa. Santiago: LegalPublishing / Thomson Reuters, 179 pp.

Vidal Domínguez, Ignacio (1997) Derecho notarial chileno. Santiago: Editorial Fallos del Mes, 517 pp.

\section{JURISPRUDENCIA UTILIZADA}

Corte Suprema. 4 de mayo de 1953. "Sociedad Iroumé Bouzout y Compañía con Empresa de los Ferrocarriles del Estado". Revista de Derecho y Jurisprudencia. T. 50, sec. 1a, pp. 127-131.

Corte Suprema. 4 de agosto de 1980. "Banco de Chile con Jimeno Valenzuela, Leonardo". Fallos del Mes. No 261, pp. 236-238.

Corte Suprema. 29 de enero de 1992. "Banco de Chile con Valdés V., Gerardo y otro". Revista de Derecho y Jurisprudencia. T. 89, sec. 1a, pp. 6-14.

Corte Suprema. 14 de junio de 1999. "Aguilar Rosas, Óscar y otros con Yaber Simon, Sergio". Revista de Derecho y Jurisprudencia. T. 96, sec. $3^{\text {a }}$, pp. 98-109.

Corte Suprema. 19 de enero de 2000. "Chaur Monsalve, Sabina y otros con Bambach Echazarreta, José". Revista de Derecho y Jurisprudencia. T. 97 , sec. 3a , pp. 20-24.

Corte Suprema. 18 de octubre de 2000. "contra Delpino Abello, Luis". Revista de Derecho y Jurisprudencia. T. 97, sec. 4a, pp. 318-322.

Corte Suprema. 5 de julio de 2001. "Cona Quijada, Alejandra con Ramdohr Janssen, Carlos". Revista de Derecho y Jurisprudencia. T. 98, sec. 3a, pp. 137-141.

Corte Suprema. 11 de agosto de 2004. "Universidad de Concepción con Comercial Eccsa S.A.". Revista de Derecho y Jurisprudencia. T. 101, sec. $1^{\text {a }}$, pp. 216-220.

Corte Suprema. 17 de agosto de 2006. "Hinostroza Sepúlveda, Teresa Susana y otros con Sucesión Vega Varas, Guillermo". Revista de Derecho y Jurisprudencia. T. 103, sec. 3a, pp. 872-877.

Corte Suprema. 22 de enero de 2008. Rol No 4960-2007, "contra Cáceres Ahuad, Carlos". Disponible en: http://microjuris.cl/ getContent?reference=MJCH_MJJ16674\&links=[MJJ16674] [fecha de visita 9 de julio de 2016]. 
Corte Suprema. 17 de marzo de 2009. Rol No 602-2008, "Banco Consosur con Huichalaf Concha, Orompello". Disponible en: http://microjuris.cl/getContent? reference $=\mathrm{MJCH}_{-}$ MJJ19777\&links=[MJJ19777] [fecha de visita 9 de julio de 2016].

Corte Suprema. 15 de julio de 2009. Rol No 2924-2008. "Barroso Barroso, María con Manterola Delgado, Carlos”. Disponible en: http:// microjuris.cl/getContent? reference $=\mathrm{MJCH}_{-}$ MJJ20453\&links=[MJJ20453] [fecha de visita 9 de julio de 2016].

Corte Suprema. 30 de marzo de 2010. Rol No 7951-2009. "Lagos Araneda, Juan con Subsecretaría de Marina del Ministerio de Defensa Nacional y Caja de Previsión de la Defensa Nacional". Disponible en: http://microjuris.cl/getContent? reference $=\mathrm{MJCH}_{-}$ MJJ23376\&links=[MJJ23376] [fecha de visita 9 de julio de 2016].

Corte Suprema. 30 de enero de 2012. Rol No 12716-2011. "Banco de Crédito e Inversiones con Sociedad Comercializadora de Productos Forestales Limitada”. Disponible en: http://microjuris.cl/ getContent?reference=MJCH_MJJ30844\&links=[MJJ30844] [fecha de visita 9 de julio de 2016].

Corte Suprema. 17 de julio de 2014. Rol No 13148-2013. "Banco Santander Chile con Inversiones e Inmobiliaria G y L". Disponible en: http://microjuris.cl/getContent? reference $=\mathrm{MJCH}_{-}$ MJJ38050\&links=[MJJ38050] [fecha de visita 9 de julio de 2016].

Corte Suprema. 17 de julio de 2014. Rol No 7240-2014. "Banco del Estado de Chile con Procam 3 S.A. y otros". Disponible en: http://microjuris.cl/getContent? reference $=\mathrm{MJCH}_{-}$ MJJ38062\&links=[MJJ38062] [fecha de visita 9 de julio de 2016].

Corte de Apelaciones de Santiago. 6 de agosto de 1963. "contra Foncea C. Luis Alberto y otra". Revista de Derecho y Jurisprudencia. T. 60, sec. $4^{\mathrm{a}}$, pp. 365-368.

Corte de Apelaciones de Santiago. 26 de mayo de 1981. "Vanni, Laura con Ortiz, Humberto". Revista de Derecho y Jurisprudencia. T. 78, sec. 2a, pp. 67-69.

Corte de Apelaciones de Santiago. 25 de octubre de 1991. "Citibank N.A. con Americana Travel Limitada". Revista de Derecho y Jurisprudencia. T. 88, sec. 2a , pp. 129-131.

Corte de Apelaciones de San Miguel. 3 de mayo de 1996. "contra Contreras Rolack, Patricio Hernán". Revista de Derecho y Jurisprudencia. T. 93, sec. 4a, pp. 152-155.

Corte de Apelaciones de Santiago. 20 de marzo de 1998. "Abumohor Raposo, Leila con Fisco". Revista de Derecho y Jurisprudencia. T. 95, sec. $2^{\text {a }}$, pp. $20-26$.

Corte de Apelaciones de Santiago. 30 de julio de 2008. Rol No 4149-2007. "Landman Rodríguez, María con Segunda 
Notaría de Providencia”. Disponible en: http://microjuris.cl/ getContent?reference=MJCH_MJJ17961\&links=[MJJ17961] [fecha de visita 9 de julio de 2016].

Corte de Apelaciones de Rancagua. 24 de febrero de 2011. Rol No 25-2009. "contra Bravo Lobos, María Lorena y otros". Disponible en: http://microjuris.cl/getContent? reference=MJCH_ MJJ26521\&links=[MJJ26521] [fecha de visita 9 de julio de 2016].

Corte de Apelaciones de Santiago. 6 de noviembre de 2015. Rol No 7891-2015. "González Landeta, Ignacio con Sistemas de Seguridad y Servicios Limitada". Disponible en: http://microjuris.cl/ getContent?reference=MJCH_MJJ42908\&links=[MJJ42908] [fecha de visita 9 de julio de 2016].

Corte de Apelaciones de Santiago. 9 de noviembre de 2015. Rol No 7709-2015. "Banco Bilbao Vizcaya Argentaria Chile con Ríos León, María”. Disponible en: http://microjuris.cl/ getContent?reference=MJCH_MJJ42934\&links=[MJJ42934] [fecha de visita 9 de julio de 2016].

Corte de Apelaciones de Chillán. 17 de febrero de 2016. Rol No 94-2016. "Carrasco Fuentes, Raúl con Tejos Henríquez, Joaquín". Disponible en: http://microjuris.cl/getContent? reference= $\mathrm{MJCH}_{-}$ MJJ43595\&links=[MJJ43595] [fecha de visita 9 de julio de 2016].

\section{OTRAS FUENTES UTILIZADAS}

Biblioteca del Congreso Nacional de Chile, Historia de la Ley $N^{\circ}$ 19.799, sobre documento electrónico, firma electrónica y los servicios de certificación de dichas firmas, 12 de abril de 2002. Disponible en: www.bcn.cl/obtienearchivo? id= recursoslegales $/ 10221.3 / 567 / 1 / \mathrm{hdl}$ 19799.pdf [fecha de visita 26 de octubre de 2016], 580 pp.

Las Siete Partidas del Sabio Rey don Alfonso el IX, glosadas por el Licenciado Gregorio López, del Consejo Real de Indias de S.M. (1829). Madrid: Oficina de D. León Amarita. T. II, 1029 pp. 